\title{
Predicting Catalysis: Understanding Ammonia Synthesis from First-Principles Calculations
}

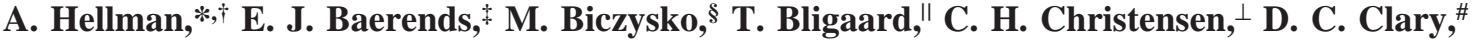 \\ S. Dahl, ${ }^{\dagger}$ R. van Harrevelt, ${ }^{\nabla}$ K. Honkala, ${ }^{\circ}$ H. Jonsson," G. J. Kroes, ${ }^{\otimes}$ M. Luppi,, U. Manthe,,${ }^{\nabla}$ \\ J. K. Nørskov, ${ }^{\circ}$ R. A. Olsen, ${ }^{\otimes}$ J. Rossmeisl, ${ }^{\circ}$ E. Skúlason, \\ A. J. C. Varandas, ${ }^{\S}$ and J. K. Vincent ${ }^{\otimes}$
}

Haldor Topsфe A/S, Nymфllevej 55, DK-2800 Lyngby, Denmark, Theoretical Chemistry Department, Free University of Amsterdam, 1081 HV Amsterdam, The Netherlands, Departamento de Quimica, Universidade de Coimbra, 3004-535 Coimbra, Portugal, Faculty of Science, VR-II, University of Iceland, 107 Reykjavík, Iceland, Center for Sustainable and Green Chemistry, Department of Chemistry, NanoDTU, Technical University of Denmark, DK-2800 Lyngby, Denmark, Physical and Theoretical Chemistry Laboratory, University of Oxford, South Parks Road, Oxford OX1 3HQ, United Kingdom, Theoretische Chemie, Technische Universität München, Lichtenbergstraße 4, D-85747 Garching, Germany, Center for Atomic-scale Materials Physics, Department of Physics, NanoDTU, Technical University of Denmark, DK-2800 Lyngby, Denmark, Leiden Institute of Chemistry, Gorlaeus Laboratories, Leiden University, P.O. Box 9502, 2300 RA Leiden, The Netherlands, and Theoretische Chemie, Universität Bielefeld, Postfach 100131, D-33501 Bielefeld, Germany

Received: December 1, 2005; In Final Form: May 27, 2006

\begin{abstract}
Here, we give a full account of a large collaborative effort toward an atomic-scale understanding of modern industrial ammonia production over ruthenium catalysts. We show that overall rates of ammonia production can be determined by applying various levels of theory (including transition state theory with or without tunneling corrections, and quantum dynamics) to a range of relevant elementary reaction steps, such as $\mathrm{N}_{2}$ dissociation, $\mathrm{H}_{2}$ dissociation, and hydrogenation of the intermediate reactants. A complete kinetic model based on the most relevant elementary steps can be established for any given point along an industrial reactor, and the kinetic results can be integrated over the catalyst bed to determine the industrial reactor yield. We find that, given the present uncertainties, the rate of ammonia production is well-determined directly from our atomic-scale calculations. Furthermore, our studies provide new insight into several related fields, for instance, gas-phase and electrochemical ammonia synthesis. The success of predicting the outcome of a catalytic reaction from first-principles calculations supports our point of view that, in the future, theory will be a fully integrated tool in the search for the next generation of catalysts.
\end{abstract}

\section{Introduction}

The discovery of nitrogen fixation from air was recently suggested $^{1}$ to be the most important scientific advancement of the 20th century. Such a statement is of course hard to verify; however, it indicates the importance of industrial ammonia

* Corresponding author. Phone: +45 4525 2525. Fax: +45 45932399.

E-mail: ahell@fysik.dtu.dk.

Haldor Topsøe A/S.

$\doteqdot$ Free University of Amsterdam.

$\S$ Universidade de Coimbra.

"University of Iceland.

${ }^{\perp}$ Department of Chemistry, NanoDTU, Technical University of Denmark.

\# University of Oxford

$\nabla$ Technische Universität München.

- Department of Physics, NanoDTU, Technical University of Denmark.

$\otimes$ Leiden University.

- Universität Bielefeld. synthesis. This point of view is further strengthened if one considers that more than $1 \%$ of the entire global energy consumption is used for ammonia production. ${ }^{2}$ The reason behind the subscribed importance is ammonia's use as a fertilizer, that is, to enhance food production. Given the increase in world population, there is no reason to suspect that the need for ammonia will be any less in the future.

Ammonia synthesis is strongly inhibited by the necessary activation of the $\mathrm{N}_{2}$ molecule. For instance, $\mathrm{N}_{2}$ activation in the gas phase requires extreme conditions, such as those present during lightning storms. Such a method for nitrogen fixation was actually commercialized during the early 20th century, but energy consumption was enormous. ${ }^{3}$ Nature uses an alternative route where the enzyme nitrogenase catalytically fixes nitrogen under ambient conditions. ${ }^{4,5}$ Mankind, however, relies on the Haber-Bosch process for its supply of ammonia. Energy consumption for this process is remarkably low, compared to 
Anders Hellman received his Ph.D. from the University of Göteborg, Sweden, in 2003. He is currently employed as a post-doc by Haldor Topsøe A/S, Denmark, working actively within the EU Network "Predicting Catalysis". His research interests include catalysis, gas-surface interactions, hot-electron chemistry, electron-hole excitations.

Evert J. Baerends obtained his Ph.D. in 1975 from the Vrije Universiteit at Amsterdam, at which university he was appointed to the chair in Theoretical Chemistry in 1981. His main research interests are the fundamental aspects of density functional theory and density matrix functional theory and the development of efficient computational methods for DFT calculations, both for finite systems (molecules, clusters) and for periodic infinite systems. At the application side, his interests comprise the analysis of chemical bonding with energy decomposition methods, with applications to transition metal chemistry and homogeneous catalysis, relativistic effects in heavy element compounds, response properties with time-dependent DFT, metalmolecule interactions (chemisorption, reaction dynamics, electronic structure analysis, and heterogeneous catalysis)

Malgorzata Biczysko obtained her Ph.D. in Theoretical Chemistry in 2000 from the University of Wroclaw, Poland. Soon after, she started to work on calculations of theoretical molecular spectra within EU RTN "Theonet II" post-doc grants at University of Bologna and University of Helsinki. Since 2004, she has been a post-doc within the EU Network "Predicting Catalysis" at University of Coimbra, working on modeling of accurate global potential energy surfaces of $\mathrm{N}_{x} \mathrm{H}_{y}$ systems. Her research interests are concentrated on the calculations of potential energy surfaces for systems where either chemical bonds or complexes are formed.

Thomas Bligaard received his Ph.D. from the Center for Atomic-scale Materials Physics (CAMP) at the Technical University of Denmark in 2003. He has subsequently been employed as a post-doc at CAMP and as an EU Network "Predicting Catalysis" post-doc at the Science Institute of the University of Iceland. His research interests are theoretical heterogeneous catalysis and materials design.

Claus H. Christensen (born Claus J. H. Jacobsen in 1968) received his M.S. in chemistry from University of Copenhagen in 1992. Until 2004, he was employed at Haldor Topsøe A/S. Now, he is professor at the Department of Chemistry, Technical University of Denmark, and Director of Danish National Research Foundation's Center for Sustainable and Green Chemistry.

David Clary received his Ph.D. from the University of Cambridge in 1977. He has been on the faculty of Manchester, Cambridge, UCL and Oxford Universities. He has published over 300 papers in the field of theoretical chemical dynamics and is a Fellow of the Royal Society. Clary is Editor of Chemical Physics Letters. He is currently President of Magdalen College, Oxford.

Søren Dahl received his Ph.D. from the Center for Atomic-scale Materials Physics (CAMP) at the Technical University of Denmark in 1999. Since then, he has worked with heterogeneous catalyst research and development at Haldor Topsøe A/S. His research interests include metal-based heterogeneous catalysis, especially kinetics and activity trends.

Rob van Harrevelt received his Ph.D. from Leiden University in 2001. He was employed as a post-doc at the Technical University Munich, working in the EU Network "Predicting Catalysis". Currently, he works as a post-doc at the Radboud University Nijmegen. His research interests are reaction and photodissociation dynamics.

Karoliina Honkala achieved her Ph.D. from the University of Oulu, Finland, in 2001. After that, she worked as a post-doc at Technical University of Denmark in the EU Network "Predicting Catalysis". At the moment, she is employed as a postdoctoral researcher in Nanoscience Center at the University of Jyväskylä in Finland. Her research interests lie in theoretical modeling of surface reactions.
Hannes Jónsson received his Ph.D. at the University of California at San Diego in 1985. After a post-doc position at Stanford University in 1986-1988, he became assistant professor and later associate and then full professor at the University of Washington in Seattle. He has now moved to become professor at the University of Iceland and director of the Chemistry Division of the University's Science Institute. His interests include the development of methods for finding the mechanism and rate of transitions from computer simulations as well as applications to diffusion and chemical reactions in solids and at the surfaces of solids.

Geert-Jan Kroes obtained his Ph.D. in Chemistry in 1990 at the University of Amsterdam, The Netherlands. He currently works as a Professor in the Theoretical Chemistry group of Leiden University. His research interests include the dynamics of reactions both in the gas phase and at surfaces and production and storage of hydrogen as a clean fuel

Marcello Luppi received his Ph.D. in Physics from University of Modena and Reggio Emilia (Italy) in 2003. He currently has a postdoc position in the Theoretical Chemistry group at the Vrije Universiteit in Amsterdam. His research interests include electronic structure calculations of molecules at metal and alloy surfaces and full dimensional potential energy surface construction and classical dynamics simulation of dissociation of diatomic molecules at flat and stepped surfaces.

Uwe Manthe studied Chemistry at the University of Mainz. He finished his Ph.D. studies in Theoretical Chemistry at the University of Heidelberg in 1991, worked as a post-doc at University of California, Berkeley, and received a Habilitation in Theoretical Physics from the University of Freiburg in 1997. After working at the Technical University Munich, he was appointed as professor for Theoretical Chemistry at the University of Bielefeld in 2004. His research focuses on the quantum dynamics and mainly studies thermal and photoinduced reactions and ultrafast nonadiabatic transitions.

Jens K. Nørskov received his Ph.D. from the University of Aarhus, Denmark, in 1979 and became professor of theoretical physics at the Technical University of Denmark in 1992. He has published more than 250 papers on surface chemistry and physics, heterogeneous catalysis, properties of nanostructures, biomolecular structure, and theoretical methods in condensed matter physics and chemistry. Nørskov is currently director of the Center for Atomic-scale Materials Physics and the Nanotechnology Center at The Technical Univeristy of Denmark, and he is chairman of the board of the Danish Center for Scientific Computing. He is a member of the Royal Danish Academy of Science and Letters and the Danish Academy of the Technical Sciences.

Roar A. Olsen received his Ph.D. from the Free University of Amsterdam, The Netherlands, in 1998, where he also continued as a post-doc for four years. He then worked as a post-doc at Leiden University, The Netherlands, for two years before becoming a lecturer in theoretical chemistry. His research interests are focused on atoms and molecules interacting with surfaces, studying both the electronic ground and excited states together with the nonadiabatic coupling of these in classical and quantum dynamics calculations.

Jan Rossmeisl received his Ph.D. from the Technical University of Denmark in 2003. He is currently employed as a post-doc at the Center for Atomic-scale Materials Physics (CAMP). His research interests are electrocatalysis and especially fuel cells.

Egill Skúlason received his M.S. degree from the University of Iceland in 2005. There, he worked on some of the calculations presented in the Biomimetic Ammonia Synthesis section as well as calculations related to hydrogen formation, in collaboration with the DTU group. Currently, he is a Ph.D. student at DTU, continuing to work in that research area. 
Christofer S. Tautermann received his Ph.D. from the University of Innsbruck, Austria, in 2003. Then, he worked as an assistant professor in the department of computer science in Innsbruck. Currently, he is employed by the University of Oxford working as a post-doc within the EU Network "Predicting Catalysis". The focus of his research lies in the accurate description of reaction dynamics, and especially in the tunneling of hydrogen.

António J. C. Varandas received a diploma in Chemical Engineering from the University of Porto in 1971 and a Ph.D. in Theoretical Chemistry from the University of Sussex in 1976. After graduation in Porto, he joined the staff at the Department of Chemistry of the University of Coimbra as Assistant Professor, where he has occupied since 1988 a position of Full Professor. His research interests are in Theoretical Chemistry, covering topics from potential energy surfaces to nonadiabatic effects in rovibrational spectroscopy and reaction dynamics, some having implications in combustion processes and ozone chemistry at the middle atmosphere. He has published over 240 papers and coauthored a monograph on Molecular Potential Energy Functions.

Jonathan Vincent received his B.S. and Ph.D. from the University of Exeter. He then went on to work at Chalmers University of Technology in Göteborg and Leiden University and currently holds a post-doc postion at Uppsala University. His current research focuses on molecular dynamics simulations of laser induced structural changes in small molecules.

other means of ammonia production, and it is well suited for large-scale manufacturing. ${ }^{6}$

The Haber-Bosch process produces ammonia from gaseous $\mathrm{N}_{2}$ and $\mathrm{H}_{2}$, which flow over a catalyst. The reaction follows a Langmuir-Hinshelwood (LH) mechanism, where both reactants are dissociatively adsorbed on a surface before any reaction between their fragments takes place; see Figure 1. Each reaction step obeys microscopic reversibility, and the elementary reaction steps are the following:

$$
\begin{gathered}
\mathrm{H}_{2}+2 * \rightleftharpoons 2 \mathrm{H} * \\
\mathrm{~N}_{2}+2 * \rightleftharpoons 2 \mathrm{~N} * \\
\mathrm{~N} *+\mathrm{H} * \rightleftharpoons \mathrm{NH} *+* \\
\mathrm{NH} *+\mathrm{H} * \rightleftharpoons \mathrm{NH}_{2} *+* \\
\mathrm{NH}_{2} *+\mathrm{H} * \rightleftharpoons \mathrm{NH}_{3} *+* \\
\mathrm{NH}_{3} * \mathrm{NH}_{3}+*
\end{gathered}
$$

where $*$ and $X *$ correspond to an empty site and an adsorbed $X$ chemical compound, respectively.

The relative simplicity and importance of ammonia synthesis has made it "the textbook example" in heterogeneous catalysis. As such, it is commonly used as a test reaction to develop new concepts and ideas. ${ }^{7}$ This is also reflected by the enormous amount of research studies in the literature, where some central works are collected in a series of monographs. ${ }^{8-10}$ Hence, it is natural that ammonia synthesis has been the very first heterogeneous catalytic reaction to be fully characterized from first principles to the extent that its productivity has been predicted for a supported technical catalyst with a surprisingly high level of accuracy. Involved studies range from the search for quantum tunneling corrections and molecular dynamics to a theoretical treatment of the nanosized catalytic particles. In this way, it differs from other first-principles studies of various catalytic reactions, such as ethylene hydrogenation, ${ }^{11}$ ethylene oxida-

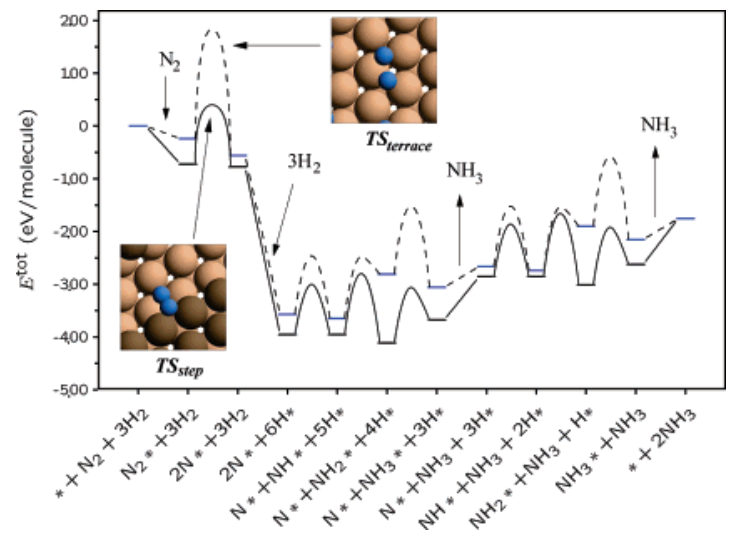

Figure 1. Calculated reaction pathways for ammonia synthesis over flat (dashed line) and stepped (solid line) Ru surfaces. The transition state configurations for $\mathrm{N}_{2}$ dissociation over the two surfaces are shown in the insets.

tion, ${ }^{12-14} \mathrm{NO}$ and $\mathrm{CO}$ reduction, ${ }^{15,16}$ selective catalytic reduction of $\mathrm{NO},{ }^{17}$ zeolite catalysis, ${ }^{18}$ and $\mathrm{CO}$ oxidation. ${ }^{19,20}$

The technology behind the Haber-Bosch process was developed by Fritz Haber ${ }^{21}$ and Carl Bosch ${ }^{22}$ almost a century ago. ${ }^{3}$ Haber first determined the thermodynamic equilibrium of ammonia under atmospheric pressure and high temperature, $1000{ }^{\circ} \mathrm{C}$, with the help of an iron (Fe) catalyst. ${ }^{23}$ Even though the amount of ammonia produced was small, the success showed that ammonia can be produced directly from gaseous $\mathrm{N}_{2}$ and $\mathrm{H}_{2}$. Later, Haber suggested more optimal operational conditions: pressures around 150-200 atm and temperatures around $500{ }^{\circ} \mathrm{C}$. Bosch solved several technical problems related to these extreme conditions and created the technology to commercialize ammonia production.

The enormous impact of their pioneering work was recognized by the scientific community. In 1918, Fritz Haber received the The Nobel Prize in Chemistry "for the synthesis of ammonia from its elements", and Carl Bosch got The Nobel Prize in Chemistry in 1931 "in recognition of his contributions to the invention and development of chemical high pressure methods".

During the period from 1909 to 1912 , Alwin Mittasch ${ }^{24}$ conducted the first ever large-scale screening experiment to find a substitute to Haber's exotic osmium- and uranium-based catalysts used at that time. All in all, some 3000 catalyst compositions were tested in about 20000 small-scale experiments. He arrived at an Fe-based catalyst, which is actually very similar to the catalyst used today. ${ }^{24}$ Although ruthenium $(\mathrm{Ru})$ was considered to be an interesting candidate during the same experiments, ${ }^{25}$ it was not until the $1970 \mathrm{~s}^{26,27}$ that $\mathrm{Ru}$ was recognized as the best elementary metal catalyst. ${ }^{28,29}$ Today, it is known that $\mathrm{Ru}$ has considerably higher activity than $\mathrm{Fe}$, at least at low temperature and close to the thermodynamic equilibrium. ${ }^{29-33}$ However, because of the higher price of $\mathrm{Ru}$ and its shorter catalytic lifetime, the dominance of iron-based catalysts has only recently been challenged by promoted $\mathrm{Ru}$ catalysts. ${ }^{34-36}$

In the 1930 s, Emmett et al..$^{37,38}$ found strong experimental evidence that $\mathrm{N}_{2}$ dissociation over $\mathrm{Fe}$ catalysts is the ratelimiting step for ammonia synthesis under industrially relevant conditions. The improvements of surface science techniques made since the late 1970s have further strengthened this view. ${ }^{39-43}$ The same is true for $\mathrm{Ru}$, as concluded by detailed self-consistent solutions of a simplified microkinetic model for ammonia synthesis. ${ }^{44,45}$ This model shows that, despite the relatively high hydrogenation barriers, $\mathrm{N}_{2}$ dissociation is rate 
limiting both in the Campbell definition ${ }^{46}$ and in the Dumesic/ de Donder sense $\mathrm{e}^{47}$ of rate determination.

In recent years, a more and more detailed molecular picture of the way solid surfaces act as catalysts for chemical reactions has emerged. During the past decades, it was concluded both from experiments $\mathrm{s}^{4-50}$ and theory ${ }^{51-55}$ that a direct link exists between the ultra-low-pressure surface science results and ammonia synthesis on $\mathrm{Fe}$ at elevated pressure and temperature. It was also shown that combining activation barriers and adsorption energies from density functional theory (DFT) calculations $^{44}$ in a microkinetic model makes it possible to predict the relative reaction rates of different catalysts. ${ }^{56}$ This, in turn, provides an explanation of the volcano curve in ammonia synthesis ${ }^{28}$ and furthermore gives the reason why a combination scheme between elements on the two sides of the volcano can result in improved catalysts. ${ }^{28,32,57,58,59}$

The purpose of the present paper is to show that modernday theory is able to, semiquantitatively, predict the turnover frequency (TOF) of an industrially relevant catalytic reaction. Here, ammonia synthesis serves as our example, as it includes most issues relevant for heterogeneous catalysis. Of course, as a catalytic reaction, it still remains simple and there are plenty of experimental results for comparison. In the paper, we give a full account of the many different aspects involved in a firstprinciples understanding of an industrially relevant catalytic reaction. Due to the complexity, we divide the problem into $\mathrm{N}_{2}$ dissociation, $\mathrm{H}_{2}$ dissociation, hydrogenation of the intermediate reactants, and the construction of a complete model for ammonia synthesis.

The paper is structured accordingly, and each subject will be presented in a separate section. In addition, we present details in ammonia gas-phase chemistry and a bioinspired way of making ammonia. In the discussion and overall conclusions section, we give the main results and put them into a more general perspective. This is followed by a short outlook.

\section{Ammonia Gas-Phase Chemistry}

Industrially relevant reactions performed through the use of heterogeneous catalysis are usually complicated multistep processes that are difficult to characterize in detail both from the experimental and theoretical points of view. Some of these processes have close analogues in elementary gas-phase reactions that can be examined by means of rigorous theories with the use of highly accurate ab initio electronic structure calculations. Such studies may help a detailed understanding of the uncatalyzed reaction paths and stand as the ground for further theoretical investigations aiming at the improvement of chemical manufacturing processes and the design of new catalysts. In the case of nitrogen hydrogenation leading to ammonia, the industrial and natural mechanisms are thought to proceed through different routes,${ }^{60}$ with nitrogen atoms being hydrogenated in industrial processes but nitrogen molecules in biological ones. It is also known that the gas-phase hydrogenation of nitrogen can occur without a catalyst only under extreme conditions due to the high energy barriers involved, although a detailed mechanism of the reaction steps has not been established thus far. Radical reactions such as $\mathrm{N}+\mathrm{H} \rightarrow \mathrm{NH}, \mathrm{NH}+\mathrm{H} \rightarrow \mathrm{NH}_{2}$, and $\mathrm{NH}_{2}+\mathrm{H} \rightarrow \mathrm{NH}_{3}$ can therefore be considered as gas-phase analogues for the Haber-Bosch processes, while gas-phase reactions related to molecular hydrogenation of nitrogen (e.g., $\mathrm{N}_{2}+\mathrm{H}_{2} \rightarrow$ $\mathrm{N}_{2} \mathrm{H}+\mathrm{H}$ and $\mathrm{NH}_{2}+\mathrm{H}_{2} \rightarrow \mathrm{NH}_{3}+\mathrm{H}$ ) would mimic elementary steps in the biological catalytic mechanism. The modeling of accurate global potential energy surfaces (PESs) for the $\mathrm{N}_{x} \mathrm{H}_{y}$ systems followed by the appropriate nuclear dynamics studies helps therefore to create a proper understanding of the elementary reactions involved in nitrogen/hydrogen chemistry. In particular, a global PES for the ground electronic state of $\mathrm{N}_{2} \mathrm{H}_{2}$ is key for dynamics studies of the addition of a first hydrogen molecule to nitrogen, which is thought to be the ratedetermining step in the hydrogenation process leading to ammonia. ${ }^{61}$

The double many-body expansion ${ }^{62}$ (DMBE) method is a well established approach for modeling accurate global PESs of small and medium sized systems. It has been successfully applied to many triatomic species (including all relevant triatomic fragments of $\mathrm{N}_{2} \mathrm{H}_{2}$ : $\mathrm{HN}_{2}\left({ }^{2} \mathrm{~A}^{\prime}\right),{ }^{63} \mathrm{NH}_{2}\left({ }^{2} \mathrm{~A}^{\prime \prime}\right),{ }^{64}$ and $\left.\mathrm{NH}_{2}\left({ }^{4} \mathrm{~A}^{\prime}\right)^{65}\right)$ as well as tetratomic (e.g., $\mathrm{HO}_{3}{ }^{66} \mathrm{HSO}_{2}{ }^{67}$ ) and even larger polyatomic $\left(\mathrm{HO}_{4}{ }^{68}\right.$ and $\left.\mathrm{HO}_{5}{ }^{69}\right)$ reactive systems. The method has been reviewed in detail elsewhere, ${ }^{62}$ and hence, only the essential aspects will be surveyed. In DMBE theory, the energy is partitioned into its dynamical correlation (dc) and extended Hartree-Fock (EHF) parts, which are both written as cluster (many-body) expansions. For an $N$-atom system, it assumes the form

$$
V\left(\mathbf{R}^{N}\right)=\sum_{n=2}^{N} \sum_{\mathbf{R}^{n} \subset \mathbf{R}^{N}}\left[V_{\mathrm{EHF}}^{(n)}\left(\mathbf{R}^{n}\right)+V_{\mathrm{dc}}^{(n)}\left(\mathbf{R}^{n}\right)\right]
$$

where $\mathbf{R}^{n}$ specifies any set of $n(n-1) / 2$ interatomic distances referring to $n$ atoms, $V_{x}^{(n)}$ are the $n$-body terms for the $x(=\mathrm{EHF}, \mathrm{dc})$-energy component, and the summations in eq 7 run over all $n$-atomic $(n \leq N)$ fragments. In DMBE theory, the extended Hartree-Fock terms, which include the nondynamical correlation, are modeled from accurate ab initio data. In turn, the dynamical correlation part that accounts for the true correlation of the electrons (and hence for the long-range induction and dispersion energy components) is approximated by physically motivated forms that are calibrated from accurate $a b$ initio data, often with the help of properties obtained via perturbation calculations. The DMBE method provides therefore a global PES that shows both the correct long-range behavior at the dissociation channels and a realistic representation dictated by the calculated ab initio energies at other regions of the molecule configuration space.

Single-valued PESs for $\mathrm{HN}_{2}\left({ }^{2} \mathrm{~A}^{\prime}\right), \mathrm{NH}_{2}\left({ }^{2} \mathrm{~A}^{\prime \prime}\right), \mathrm{NH}_{2}\left({ }^{4} \mathrm{~A}^{\prime}\right)$, and $\mathrm{N}_{2} \mathrm{H}_{2}\left({ }^{1} \mathrm{~A}\right)$, which are possible fragments of $\mathrm{N}_{x} \mathrm{H}_{y}$, were constructed through a procedure that involves the calculation of many thousands of high-level ab initio points. The multireference configuration interaction (MRCI) ${ }^{70}$ method with the augcc-pVQZ basis set of Dunning (AVQZ) ${ }^{71,72}$ and the full valence complete active space (FVCAS) $)^{73}$ wave function has generally been utilized. All calculations were performed using the $\mathrm{MOLPRO}^{74}$ suite of programs.

For $\mathrm{HN}_{2}\left({ }^{2} \mathrm{~A}^{\prime}\right), \mathrm{NH}_{2}\left({ }^{2} \mathrm{~A}^{\prime \prime}\right)$, and $\mathrm{NH}_{2}\left({ }^{4} \mathrm{~A}^{\prime}\right)$, ab initio data points were corrected by the DMBE-SEC ${ }^{75}$ [DMBE-scaling of the external (dynamical) correlation] method. For $\mathrm{N}_{2} \mathrm{H}_{2}$, the DMBE form ${ }^{76}$ employed as building blocks the functions of similar type already reported for $\mathrm{NH}_{2}\left({ }^{2} \mathrm{~A}^{\prime \prime}\right),{ }^{64} \mathrm{NH}_{2}\left({ }^{4} \mathrm{~A}^{\prime}\right),{ }^{65}$ and $\mathrm{HN}_{2}\left({ }^{2} \mathrm{~A}^{\prime}\right) .{ }^{63}$ Care was taken of the fact that dissociation of $\mathrm{N}_{2} \mathrm{H}_{2}$ correlates with the doublet state of atomic nitrogen at some regions of configuration space while at others it involves its ground state. Moreover, the electrostatic energy terms were added to account for dipole-dipole, dipole-quadrupole, and quadrupole-quadrupole interactions. Local four-body energy terms of the extended Hartree-Fock type have also been added to mimic the relevant stationary points as determined from ab initio 


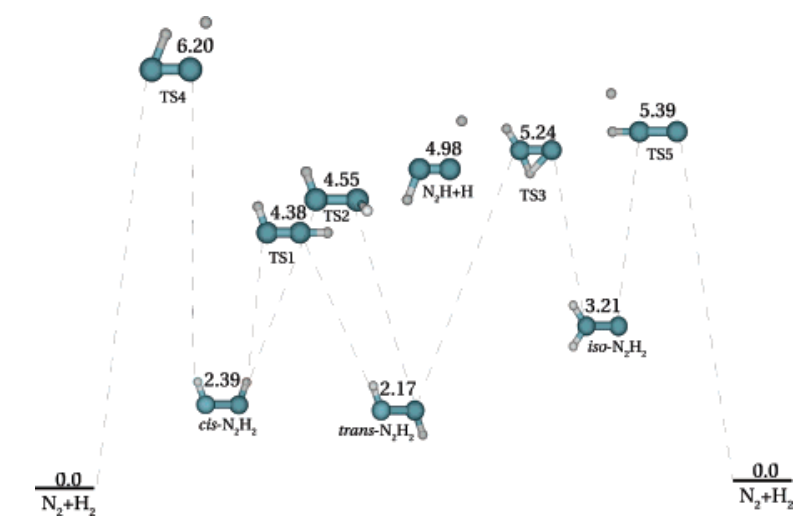

Figure 2. Positions of the stationary points on the global potential energy surface for $\mathrm{N}_{2} \mathrm{H}_{2}$ relative to the $\mathrm{N}_{2}+\mathrm{H}_{2}$ limit. All energies are in electronvolts, calculated at the MRCI $(+Q) /$ aug-cc-pVQZ//FVCAS/ aug-cc-pVQZ level and corrected for zero-point energy.

calculations at the MRCI/aug-cc-pVQZ level subsequently corrected for size consistency according to the Davidson $(+Q)^{77}$ scheme. The accuracy of such an approach was tested by comparison with the heat of formation of trans $-\mathrm{N}_{2} \mathrm{H}_{2}$. The results show $^{78}$ that relative, zero-point-energy-corrected, $\mathrm{MRCI}(+\mathrm{Q}) /$ aug-cc-pVQZ energies agree to chemical accuracy with the best experimental ${ }^{79}$ and theoretical ${ }^{80}$ results. By further scaling the ab initio dynamical correlation energy of the $\mathrm{N}_{2} \mathrm{H}_{2}$ system, after the Davidson corrections were put in, not only the good relative positions for the minima and saddle points were maintained but also the correct exothermicities insured for all dissociation channels. ${ }^{76}$ We emphasize that the single-valued DMBE form for $\mathrm{N}_{2} \mathrm{H}_{2}$ and its fragments includes a proper description of long-range forces at all asymptotic channels. Moreover, the geometry and spectroscopy of the main stationary points are reproduced accurately when compared with the best available theoretical ${ }^{80-83}$ and experimental ${ }^{79,84}$ data. In fact, the above DMBE potential energy surfaces ${ }^{63-65,76}$ probably stand as the most accurate representations published thus far, being commended for both quantum ${ }^{85,86}$ and classical ${ }^{87}$ dynamics studies of the associated reactions.

The reaction mechanism of the $\mathrm{N}_{2} / \mathrm{H}_{2}$ conversion to $\mathrm{NH}_{3}$ has been recently studied by Hwang and Mebel with G2M(MP2)// MP2/6-31G** theory. ${ }^{61}$ Further insight was obtained by analyzing features of relevant $\mathrm{N}_{x} \mathrm{H}_{y}$ DMBE surfaces. For the molecular mechanism of nitrogen hydrogenation, the $\mathrm{N}_{2} \mathrm{H}_{2}{ }^{76}$ PES is required for studies of the first reaction step. For diazene formation from $\mathrm{N}_{2}$ and $\mathrm{H}_{2}$, the perpendicular approach of the reactant molecules leading to iso- $\mathrm{N}_{2} \mathrm{H}_{2}$ via TS5 was found to be favorable over the parallel one leading to $c i s-\mathrm{N}_{2} \mathrm{H}_{2}$ via TS4. ${ }^{78}$ Moreover, it was established ${ }^{61,78}$ that in both cases barriers of more then $5.2 \mathrm{eV}$ relative to the $\mathrm{N}_{2}+\mathrm{H}_{2}$ dissociation limit are involved; see Figure 2 for the relative stabilities of the major stationary points and Figure 3 for sample two-dimensional cuts of the global $\mathrm{N}_{2} \mathrm{H}_{2}$ DMBE potential energy surface at its current stage of development. On the other hand, no barrier was found for $\mathrm{N}_{2} \mathrm{H}_{2}$ formation from any of the radical channels: $\mathrm{NH}+\mathrm{NH}, \mathrm{NH}_{2}+\mathrm{N}$, and $\mathrm{N}_{2} \mathrm{H}+\mathrm{H}$ (see Figure 3). Such a result implies that radical processes are strongly favored when compared to the formation of $\mathrm{N}_{x} \mathrm{H}_{y}$ species from molecular nitrogen and hydrogen. In particular, this suggests that the presence of hydrogen radicals can promote hydrogenation of molecular nitrogen. It may also explain why ammonia formation can occur under extreme conditions such as lightning where radicals are likely to be present. For the

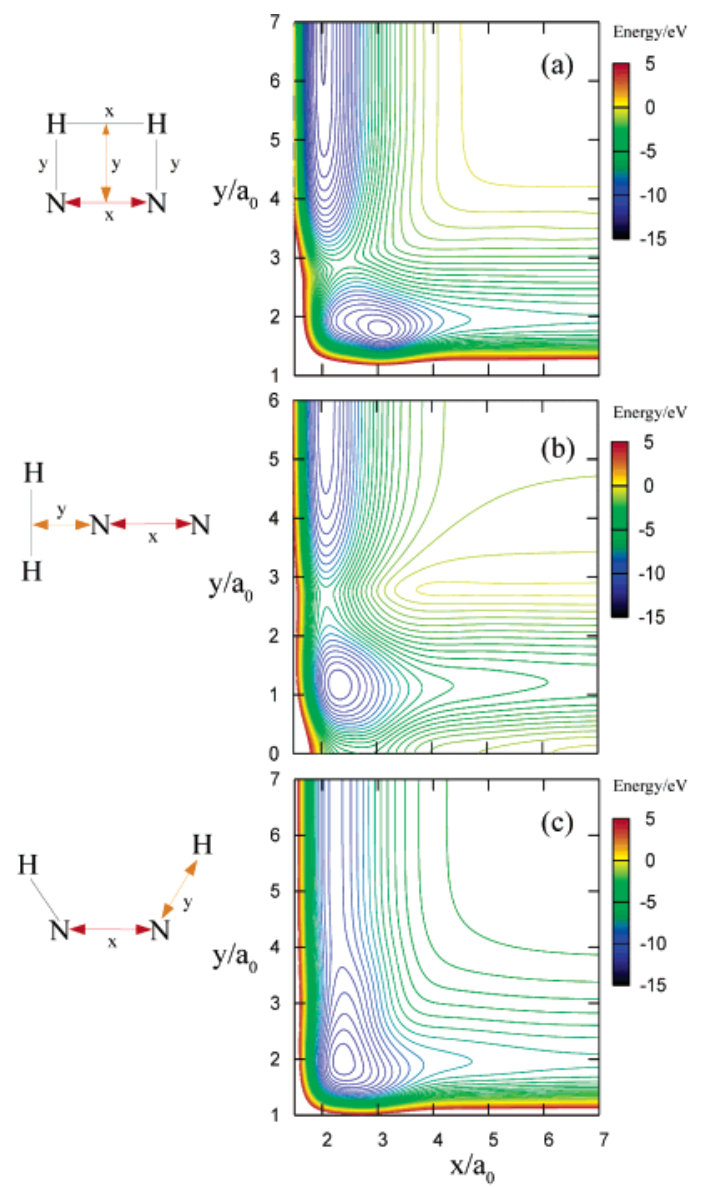

Figure 3. Selected $2 \mathrm{D}$ cuts of global DMBE-PES for $\mathrm{N}_{2} \mathrm{H}_{2}\left({ }^{1} \mathrm{~A}\right)$. The contour lines span the energy interval $[-15.0,5.0] \mathrm{eV}$ in steps of 0.5 $\mathrm{eV}$. All energies are relative to the atomic limit $(2 \mathrm{~N}+2 \mathrm{H})$. (a) Contour plot for the parallel approach of $\mathrm{N}_{2}$ and $\mathrm{H}_{2}$, with the $x$-axis corresponding to the $\mathrm{N}-\mathrm{N}$ and $\mathrm{H}-\mathrm{H}$ distances and the $y$-axis to the distance between the center of mass of both molecules (note that the $\mathrm{N}_{2} \mathrm{H}_{2}$ structure is distorted from the cis- $\mathrm{N}_{2} \mathrm{H}_{2}$ minimum). (b) Contour plot for the perpendicular approach of $\mathrm{N}_{2}$ and $\mathrm{H}_{2}$, with the $x$-axis corresponding to the $\mathrm{N}-\mathrm{N}$ distance and the $y$-axis to the distance between the center of mass of $\mathrm{H}_{2}$ and one of the nitrogen atoms (the $\mathrm{H}-\mathrm{H}$ distance is kept fixed at $3.0 a_{0}$, which compares with the value of $3.2861 a_{0}$ for the iso $-\mathrm{N}_{2} \mathrm{H}_{2}$ minimum). (c) Contour plot for the $\mathrm{H}+$ $\mathrm{N}_{2} \mathrm{H} \rightarrow \mathrm{NH}+\mathrm{NH}$ channel; the $x$-axis ( $y$-axis) denotes the $\mathrm{N}-\mathrm{N}(\mathrm{N}-$ $\mathrm{H})$ distance, with all other distances and angles being kept fixed at the values corresponding to the $c i s-\mathrm{N}_{2} \mathrm{H}_{2}$ minimum.

radical mechanism, it has already been proposed ${ }^{61}$ that the reaction

$$
\mathrm{N}_{2}+\mathrm{H} \rightarrow \mathrm{N}_{2} \mathrm{H}
$$

and subsequent chain reactions may be key for uncatalyzed nitrogen hydrogenation. The $\mathrm{N}_{2} \mathrm{H}$ DMBE form ${ }^{63}$ predicts two symmetry-related metastable minima, which lie $0.20 \mathrm{eV}$ above the $\mathrm{N}_{2}+\mathrm{H}$ asymptote and $0.46 \mathrm{eV}$ below the corresponding transition states (Figure 4), in good agreement with the best available theoretical results. ${ }^{81}$ On the basis of this PES estimation of the thermal high pressure, direct and reverse rate constants were established for the reaction of the unimolecular decomposition of $\mathrm{N}_{2} \mathrm{H}$, which is of relevance in nitrogen combustion chemistry.

In summary, the above DMBE potential energy surfaces give insight into the first steps of molecular and radical hydrogenation of $\mathrm{N}_{2}$ leading to ammonia production. To fully understand such gas-phase reactions and search for less unfavorable gas-phase 


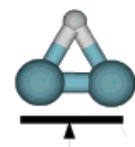

(a)

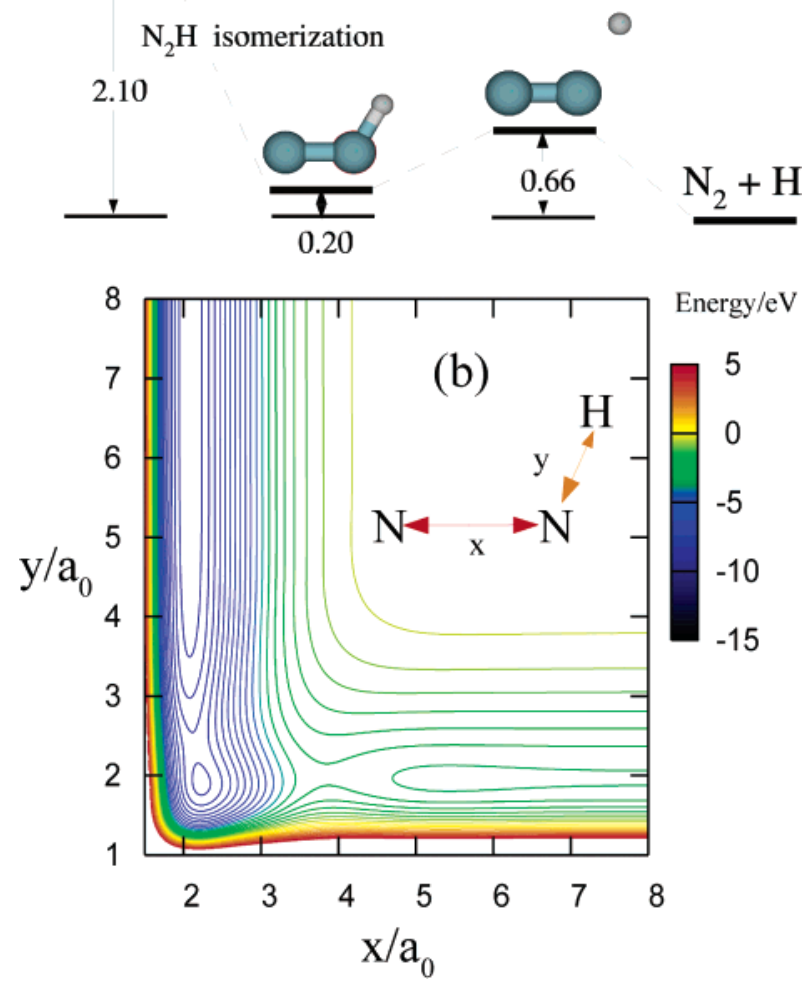

Figure 4. Stationary points and 2D cut of the DMBE potential energy surface for $\mathrm{HN}_{2}\left({ }^{2} \mathrm{~A}^{\prime}\right)$. In panel a, the energies are in electronvolts and relative to the $\mathrm{N}_{2}+\mathrm{H}$ asymptote, while, in panel $\mathrm{b}$, they are relative to the atomic limit $(2 \mathrm{~N}+\mathrm{H})$. The energy contours start at $-15.0 \mathrm{eV}$, being equally spaced by $0.5 \mathrm{eV}$.

mechanisms, further work is required to generate additional global $\mathrm{N}_{x} \mathrm{H}_{y}$ potential energy surfaces.

\section{Quantum Rate Calculations on $\mathbf{N}_{2}$ Dissociation}

In heterogeneous ammonia synthesis, nitrogen molecules do not directly react with hydrogen. Instead, dissociative adsorption of nitrogen on the catalyst surface precedes the hydrogenation reactions. The dissociation of $\mathrm{N}_{2}$ is the rate-limiting step in the overall ammonia synthesis process; that is, it is the reaction with the lowest reaction rate under synthesis conditions; ${ }^{44,45}$ see the introduction part. The rate constant for this reaction is therefore an essential input parameter in kinetic models predicting the rate of ammonia synthesis.

In section VI, the reaction rate for dissociative adsorption of $\mathrm{N}_{2}$ is calculated using harmonic transition state theory (TST). However, this treatment neglects quantum effects. Several authors have suggested that quantum tunneling is important for dissociative adsorption of $\mathrm{N}_{2} \cdot{ }^{88-93}$ Therefore, the question arises if TST can be used to predict the rate of ammonia production. To answer this question, we performed quantum dynamics calculations for the rate of dissociative adsorption of $\mathrm{N}_{2}$ on a stepped $\mathrm{Ru}(0001)$ surface. A realistic PES based on DFT calculations ${ }^{94}$ was employed. In this section, the tunneling effect is examined by comparing the rate constants obtained from the exact quantum calculations and from classical harmonic TST.

Accurate quantum mechanical calculations of the rate constant are possible without solving the full scattering problem. Employing flux correlation functions, ${ }^{95-97}$ reaction rates can be

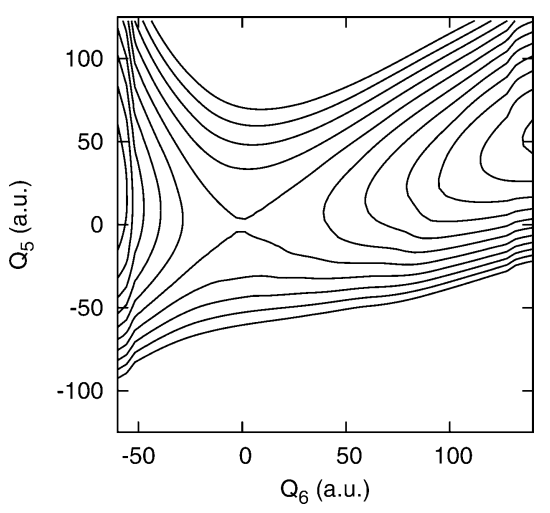

Figure 5. Potential energy surface for $\mathrm{N}_{2}$ on $\mathrm{Ru}$, as a function of normal coordinates $Q_{5}$ and $Q_{6}\left(Q_{1}-Q_{4}\right.$ are relaxed). The equipotential lines are for energies between 0.7 and $1.2 \mathrm{eV}$, with a spacing of 0.05 $\mathrm{eV}$.

calculated by dynamical simulations restricted to the region in the vicinity of the reaction barrier. The underlying theory is exact; that is, it yields rigorously correct thermal rate constants, $k(T)$, and cumulative reaction probabilities, $N(E)$ (i.e., the sum of the initial state selected reaction probabilities for all possible initial states), for the given dynamical model. The present work employs a scheme described in detail in ref 98.

To further increase the efficiency of the calculations, the multiconfiguration time-dependent Hartree (MCTDH) approach $^{98-101}$ is employed for real and imaginary time propagations in the dynamical simulations. The MCTDH method is an exact time-dependent wave packet method using timedependent basis functions. These basis functions, called singleparticle functions, form an optimal basis set for the wave function representation. Since the MCTDH method is particularly efficient for direct processes, which typically occur on a short time scale, it is ideally suited for calculations of rate constants of activated processes.

In the dynamical model, all six nitrogen degrees of freedom are included, while the positions of the surface atoms are frozen. The six-dimensional (6D) PES for the transition state region is constructed by interpolation of DFT data using the Shepard interpolation scheme. ${ }^{94}$ Figure 5 shows a contour plot of the potential energy as a function of the transition state normal modes $Q_{5}$ and $Q_{6}$, with optimized coordinate values for $Q_{1}-$ $Q_{4}$ in the neighborhood of the transition state. $Q_{6}$ is the reaction coordinate; it corresponds mainly to $\mathrm{N}-\mathrm{N}$ stretching, while mode $Q_{5}$ mainly involves the motion of $\mathrm{N}_{2}$ perpendicular to the surface. The barrier height of $1.0 \mathrm{eV}$ is significantly larger than the barrier height obtained from the DFT calculations described in section VI $(0.49 \mathrm{eV})$. This difference results from the frozen (this section) and relaxed (section VI) treatment of the surface atoms. Relaxation of the surface atoms thus has a large effect on the barrier height (the energy difference between the asymptotic area and the transition state region); it yields only minor modifications of the shape of the PES in the vicinity of the transition state. ${ }^{102}$ Thus, the magnitude of the tunneling effect will be very similar independent of whether frozen or relaxed surface atoms are used in the dynamical model.

The accurate quantum mechanical rate constant for the sixdimensional model was calculated using the methodology outlined above. See ref 94 for details of the calculations. The ratio between the accurate quantum mechanical result and the result of harmonic TST (employing the same PES) is presented in Figure 6. Figure 6 clearly shows that harmonic TST yields an adequate description for temperatures above room temperature. Even at a temperature as low as $200 \mathrm{~K}$, the TST result 


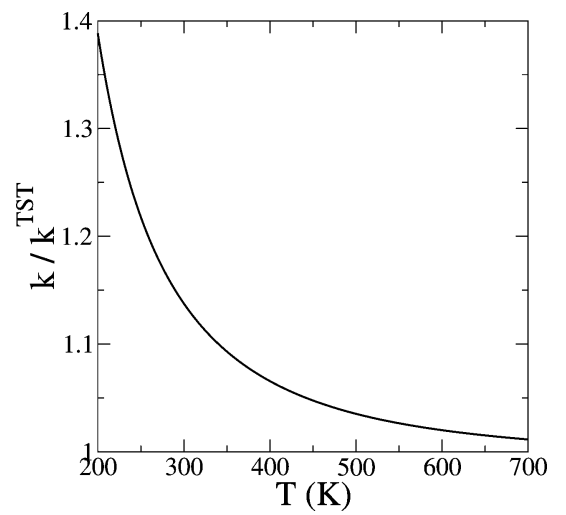

Figure 6. Ratio of the accurate quantum rate constant for $\mathrm{N}_{2}$ dissociation, $k$, and the harmonic TST result, $k^{\mathrm{TST}}$, as a function of the temperature.

and the accurate quantum result differ by less than a factor of 1.4. Since quantum tunneling is neglected in TST, the good agreement between harmonic TST and accurate quantum results shows that quantum tunneling is not important for $\mathrm{N}_{2}$ dissociation on $\mathrm{Ru}$ or other related systems. Thus, theoretical data based on TST calculations can therefore reliably be used as input data for kinetic models predicting the rate of ammonia production.

\section{Quantum Dynamical Calculations on $\mathbf{H}_{2}$ Dissociation}

Because the dissociative chemisorption of $\mathrm{H}_{2}$ on $\mathrm{Ru}$ is one of the elementary reaction steps involved in ammonia production, it is also important to have an in-depth understanding of this step. Therefore, we have performed detailed quantum dynamical calculations on the dissociation of $\mathrm{H}_{2}$ on the (0001) face of $\mathrm{Ru}$, as a large fraction of the surface area of $\mathrm{Ru}$ nanoparticles corresponds to this face. ${ }^{103}$

It has been shown that reasonably accurate probabilities for the dissociation of $\mathrm{H}_{2}$ on metal surfaces can now be calculated, thanks to three recent developments. First, the use of the generalized gradient approximations (GGAs) to the exchangecorrelation energy ${ }^{104,105}$ makes it possible to compute fairly accurate molecule-surface interaction energies. Moreover, application of periodic boundary conditions in either a threedimensional (3D) supercell approach ${ }^{106}$ or a two-dimensional (2D) slab approach ${ }^{107}$ ensures the rapid convergence of these energies. Second, the DFT data can now be accurately represented in global PESs, using for instance the corrugation reducing procedure (CRP). ${ }^{108,109}$ Third, quantum dynamical methods in which the motion of all six degrees of freedom of $\mathrm{H}_{2}$ can be treated accurately, with essentially no approximations, ${ }^{110-112}$ have been developed. Recent 6D quantum dynamics calculations based on DFT-obtained PESs interpolated with the CRP method gave good agreement with experimental dissociation probabilities for $\mathrm{H}_{2}+\operatorname{Pd}(111)^{113}$ and $\operatorname{Pt}(111) .^{112}$

The goals of the DFT and time-dependent wave packet (TDWP) calculations on $\mathrm{H}_{2}+\mathrm{Ru}(0001)$ were twofold. The main goal was to predict the reaction rate for the dissociative chemisorption of $\mathrm{H}_{2}$ on a much exposed surface of $\mathrm{Ru}$ nanoparticles (i.e., the 0001 face) for use in modeling of ammonia production from first principles. The second goal was to test the accuracy of two different but widely used GGA functionals (the Perdew-Wang-91 (PW91) ${ }^{104}$ and the revised Perdew-Burke-Ernzerhof (RPBE) ${ }^{105}$ functionals), by predicting reaction probabilities as a function of the collision energy for dissociative chemisorption of $\mathrm{H}_{2}$ on the clean $\mathrm{Ru}(0001)$ surface. Hopefully, future experimental work will show us which functional performs best for this system. Note that, in principle, calculations of an elementary dissociation reaction on a bare surface, such as those discussed here for $\mathrm{H}_{2}+\mathrm{Ru}(0001)$, form an even more stringent test of the PES accuracy than calculations on the overall rate of a catalytic reaction (as presented here for the formation of ammonia over $\mathrm{Ru}$ nanoparticles). In the latter case, the effect of barriers being too low (too high) is usually compensated by the effect of the chemisorption energy of reaction intermediates being too high (low), leading to a coverage that is too high (low); ${ }^{114}$ see section VI.

The PES for the interaction of the $\mathrm{H}_{2}$ molecule with the bare $\mathrm{Ru}(0001)$ surface was obtained using a combination of DFTGGA calculations and interpolation techniques. ${ }^{115}$ In the DFTGGA calculations, the $\mathrm{Ru}(0001)$ surface was modeled within a supercell approach using a three-layer slab. The interlayer distance was relaxed by total energy calculations, and each layer was built using a $(2 \times 2)$ unit cell. The $(2 \times 2)$ cell is large enough to prevent undesired interactions between the periodically repeated $\mathrm{H}_{2}$ molecules. A vacuum region of $13.1 \AA$ along the direction perpendicular to the surface plane was included in the supercell construction.

The $\mathrm{Ru}(0001)$ surface has a $C_{3 v}$ symmetry, but in order to reduce the number of $2 \mathrm{D}$ cuts needed for the interpolation, we imposed a $C_{6 v}$ symmetry, which effectively means that the small difference between hexagonal close-packed (hcp) and facecentered cubic (fcc) hollow sites in the surface layer (see Figure $7 a)$ is neglected. This approximation was carefully checked, and the errors introduced were found to be negligible for the purpose of our work. ${ }^{115}$

The first-principles data sets for the interpolation were calculated employing DFT as implemented in the DACAPO code. ${ }^{116}$ The electronic wave functions were expanded in a basis set of plane waves, and the ion cores were described by nonlocal ultrasoft pseudopotentials. A GGA level of theory was adopted for the self-consistent electron density using the PW91 exchangecorrelation functional. The energies were derived using both the PW91 and RPBE functionals, in the latter case by post-scf calculations.

On the basis of the DFT-GGA calculated potential energies, an analytical 6D PES was built using the CRP. ${ }^{108,109}$ This method proved to provide very accurate interpolation results for $\mathrm{H}_{2}$ molecules interacting with several metal surfaces. ${ }^{108,109,115,117,118}$ The essence of the method is that the interpolation is not carried out on the highly corrugated DFTGGA data itself but on the much smoother interpolation function obtained by first subtracting the separate atomic interactions with the surface. Details of the approach, and the interpolation techniques employed, can be found in refs 108 and 109.

Reaction probabilities and rate constants for dissociative chemisorption of $\mathrm{H}_{2}$ on bare $\mathrm{Ru}(0001)$ were computed ${ }^{119}$ by solving the time-dependent Schrödinger equation using the TDWP method. ${ }^{120}$ The implementation of the TDWP method we use for surfaces of hexagonal symmetry is described in ref 112. The method makes use of the discrete variable representation (DVR) for four of the six degrees of freedom of $\mathrm{H}_{2}$ and of a nondirect product finite basis representation ${ }^{121}$ for the two remaining degrees of freedom, that is, the angles of orientation of the molecule. All six molecular degrees of freedom are treated quantum mechanically, with essentially no approximations. The wave function is propagated in time using the split-operator method, ${ }^{122}$ starting from a suitably chosen initial wave function representing the molecule moving toward the surface at normal incidence, in a given initial rovibrational state, and with a range of initial translational energies normal to the surface. The part of the wave function that is reflected from the surface is analyzed 


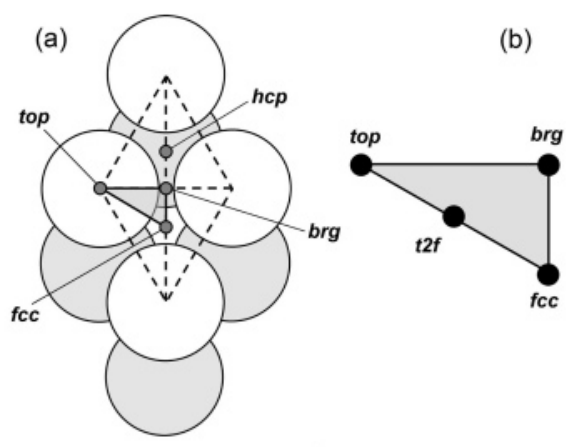

$r(A)$

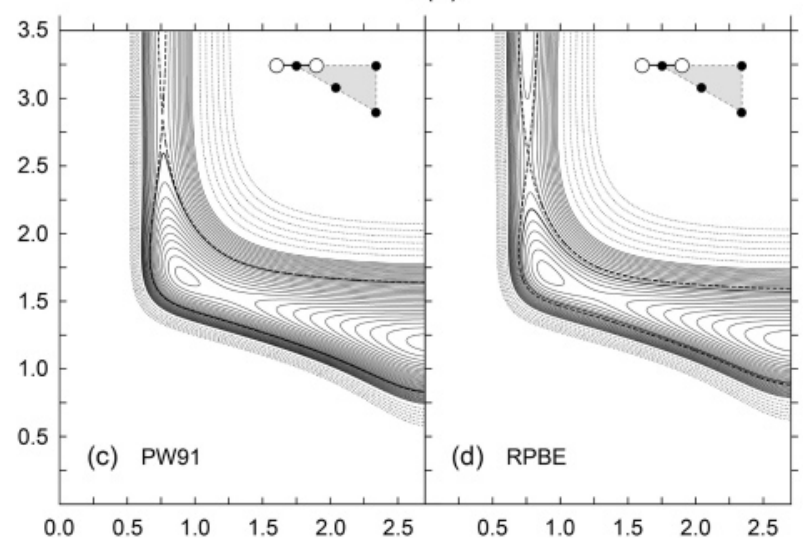

Figure 7. (a) $C_{3 v}$ high-symmetry adsorption sites for the $\mathrm{Ru}(0001)$ surface are shown: top, brg, fcc, and hcp. The dashed lines highlight the $(1 \times 1)$ surface cell; the shaded-grey triangle (solid line) defines the irreducible zone if a $C_{6 v}$ surface symmetry is imposed (i.e., assuming the hcp and the fcc sites to be equivalent). (b) Enlarged view of the $C_{6 v}$ irreducible surface unit cell. The black-filled circles indicate the four sites used for the construction of the 6D PES. (c and d) 2D contourplots ( $z$, distance from the surface; $r, \mathrm{H}-\mathrm{H}$ distance) of the PW91 and RPBE PESs for the most reactive configuration. The zero of the potential energy scale is set at the energy of infinite gas-surface separation for each of the two functionals. The solid line contours span the interval $[-1,0.6] \mathrm{eV}$ at steps of $50 \mathrm{meV}$. The dotted line contours span the interval[ $0.8,1.8] \mathrm{eV}$ at steps of $200 \mathrm{meV}$. The zero contour is indicated by a bold solid line. The contour at the energy of the first barrier (for each 2D cut and functional) is indicated by the bold dashed line. The insets show the orientation of the $\mathrm{H}_{2}$ molecule (white circles) with respect to the four main adsorption sites (black circles) in the irreducible zone, with $\mathrm{H}_{2}$ taken parallel to the surface.

to obtain S-matrix elements ${ }^{123}$ for diffractionally, rotationally, and vibrationally (in)elastic scattering. From the S-matrix column that is calculated, probabilities, $P_{\text {if }}\left(E_{z}\right)$, are extracted for scattering from the initial state, $\mathrm{i}$, to the final state, $\mathrm{f}$, at the normal translational energy, $E_{z}$. Summation of these probabilities yields the reflection probability, and subtraction from unity yields the initial state resolved reaction probability, $R_{\mathrm{i}}\left(E_{z}\right)$. Assuming (i) that normal energy scaling (NES) applies (i.e., that the reaction probability only depends on the component of the collision energy normal to the surface) and (ii) that the reaction probability is independent of the initial rovibrational state of $\mathrm{H}_{2}$, the rate constant for reaction can then be computed from

$$
k_{\mathrm{r}}(T)=\frac{p}{k_{\mathrm{B}} T} \sqrt{\frac{M}{2 p k_{\mathrm{B}} T}} \int_{0}^{\infty} v_{z} R_{\mathrm{i}}\left(v_{z}\right) \exp -\frac{m v_{z}^{2}}{2 k_{\mathrm{B}} T} \mathrm{~d} v_{z}
$$

with $\mathrm{i}=(v=0, j=0)$. In eq $9, p$ is pressure, $m$ is the mass of $\mathrm{H}_{2}$, and $v_{z}$ is the initial velocity of the molecule normal to the surface and corresponding to the translational energy, $E_{z}$. Approximation ii was shown to work well for the
TABLE 1: Barrier Heights, $E_{\mathrm{B} 1}$, and Locations $(z$, Distance from the Surface; $r, \mathrm{H}-\mathrm{H}$ Distance) of the Lowest Barriers for Dissociation of $\mathbf{H}_{2}$ Molecules Parallel to the Ru Surface ${ }^{a}$

\begin{tabular}{lllll}
\hline & top & t2f & brg & fcc \\
\hline$E_{\mathrm{B} 1}^{\mathrm{PW} 91}(\mathrm{meV})$ & 13 & 69 & 174 & 254 \\
$E_{\mathrm{B} 1}^{\mathrm{RPE}}(\mathrm{meV})$ & 85 & 184 & 333 & 436 \\
$z_{\mathrm{B} 1}^{\mathrm{PW} 1}(\AA)$ & 2.92 & 2.45 & 2.10 & 2.00 \\
$z_{\mathrm{B} 1}^{\mathrm{RPE}}(\AA)$ & 2.58 & 2.27 & 1.98 & 1.86 \\
$r_{\mathrm{B} 1}^{\mathrm{PW} 1}(\AA)$ & 0.76 & 0.77 & 0.79 & 0.80 \\
$r_{\mathrm{B} 1}^{\mathrm{PW} 91}(\AA)$ & 0.77 & 0.78 & 0.80 & 0.81
\end{tabular}

${ }^{a}$ The PW91 and RPBE results obtained for the four adsorption sites reported in Figure $7 \mathrm{~b}$ are shown. The barrier height is calculated with respect to the energy of infinite gas-surface separation.

TABLE 2: Energetic (EC) and Geometric (GC) Corrugation of the PW91 and RPBE PESs ${ }^{a}$

\begin{tabular}{cll}
\hline corrugation & PW91 & RPBE \\
\hline energetic $(\mathrm{meV})$ & 240 & 350 \\
geometric $(\AA)$ & 0.92 & 0.73
\end{tabular}

${ }^{a}$ The EC is obtained as the difference between the lowest barrier height at the site displaying the lowest overall barrier height and the lowest barrier height at the site displaying the highest overall barrier height for an $\mathrm{H}_{2}$ molecule oriented parallel to the surface. The geometric corrugation is the difference in the surface distance at which the barrier is located, between the earliest and the latest barrier.

$\mathrm{H}_{2}+\mathrm{Pt}(111)$ system, ${ }^{124}$ which is similar to $\mathrm{H}_{2}+\mathrm{Ru}(0001)$ (it is activated and exhibits early barriers over a similar energy range), but the first approximation (i) needs further testing.

The results of the 6D PES interpolation were carefully tested in order to determine the agreement with the (pointwise) firstprinciples data. The average error in the interpolation with respect to the DFT-GGA energies is found to be about $3 \mathrm{meV}$ and the maximum error not larger than about $30 \mathrm{meV}$ in the regions of the configuration space that are important for the quantum dynamics simulations (i.e., in the entrance channel where the first reaction barriers are located). These numbers prove the high accuracy achieved in the construction.

The two GGA functionals employed produce rather distinct PESs. The differences were investigated in detail. Though both functionals predict the lowest barrier to dissociation on top of a $\mathrm{Ru}$ atom with the $\mathrm{H}_{2}$ molecule oriented parallel to the surface (see the related 2D cut of the PES in Figure 7), the PW91 PES shows a higher reactivity than the RPBE PES, with lower-energy and earlier located (farther from the $\mathrm{Ru}$ surface) dissociation barriers (see Table 1). A possible reason for the dissociation barriers being lower for the PW91 functional is that this functional yields more overbinding for atom-surface and molecule-surface interactions than the RPBE functional, ${ }^{105}$ noting that the PBE functional typically yields results very similar to the PW91 functional.

The differences in barriers between the two PESs increase when moving from the site with the lowest barrier toward those with higher barriers and in general for the $\mathrm{H}_{2}$ molecule getting closer to the surface. Moreover, the energetic corrugation (range of barrier heights) displayed by the RPBE PES is larger than the PW91 PES while the geometric corrugation (range of barrier positions) is smaller (see Table 2).

In conclusion, reaction probabilities computed for $\mathrm{H}_{2}+\mathrm{Ru}-$ (0001) with the PW91 and the RPBE PES are compared in Figure 8 . In both cases, the reaction probability curves exhibit a monotonic increase with increasing collision energy. This energy dependence is characteristic for activated reactions such 


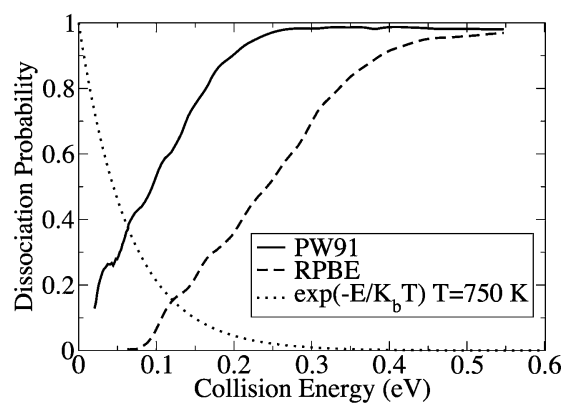

Figure 8. Dissociation probability of $(v=0, j=0) \mathrm{H}_{2}$ colliding with $\mathrm{Ru}(0001)$ at normal incidence shown as a function of the collision energy. Results are presented of TDWP calculations employing PESs generated using the PW91 GGA and RPBE GGA functionals. Also plotted is $\exp \left(-E / k_{\mathrm{B}} T\right)$ for $T=750 \mathrm{~K}$, to show how the reaction probabilities are weighted in the calculation of the rate constant at this temperature.

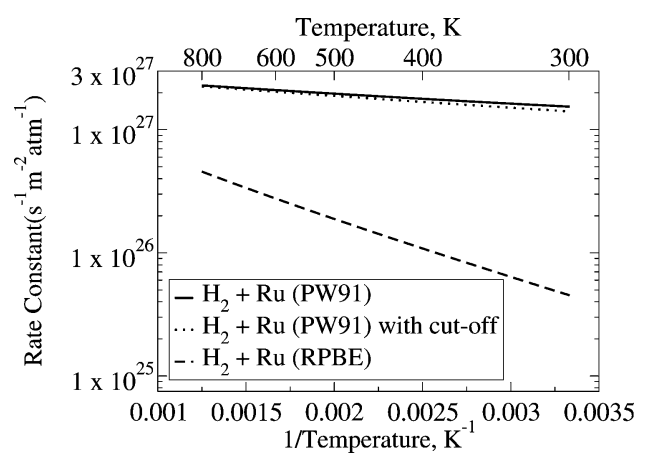

Figure 9. Rate constants for dissociation of $\mathrm{H}_{2}$ on $\mathrm{Ru}(0001)$ plotted against temperature. The rate constants are based on reaction probabilities computed using the TDWP method and two PESs, that is, the PW91 and RPBE PESs (see text for details). The main PW91 results use linear extrapolation of the reaction probability to zero below the lowest calculated value of $0.02 \mathrm{eV}$ (see ref 119 for details). The PW91 cutoff results assume that the reaction probability is zero below 0.02 $\mathrm{eV}$.

as $\mathrm{H}_{2}+\mathrm{Pt}(111),{ }^{112,125} \mathrm{Cu}(100),{ }^{111}$ and $\mathrm{Cu}(111)^{126}$ and simply reflects the fact that both the PW91 and RPBE PESs exhibit barriers for all impact sites. (Note that the definite proof that the $\mathrm{H}_{2}+\mathrm{Pt}(111)$ reaction is activated comes from experiments. ${ }^{125}$ DFT calculations ${ }^{127,128}$ employing the PW91 functional $^{129}$ suggest the reaction to be nonactivated at some sites. However, DFT calculations using the Becke-Perdew (BP) exchange-correlation functional show the reaction to be activated on all sites, and six-dimensional quantum dynamics calculations employing the BP PES show excellent agreement with experiment for both reaction ${ }^{112,130}$ and diffraction. ${ }^{130}$ ) Use of the PW91 PES yields a much higher reaction probability than use of the RPBE PES, and the PW91 reaction probability curve is narrower. These dynamics results reflect that the lowest barrier is obtained with the PW91 PES and that the range of barrier energies is narrower for the PW91 PES than for the RPBE PES. The reaction probability curves are clearly distinct, and future molecular beam experiments should be able to determine which of the two GGA functionals describes the dissociation of $\mathrm{H}_{2}$ on $\mathrm{Ru}(0001)$ best, assuming that measured reaction probabilities would not fall midway between the predicted curves.

Rate constants computed from the PW91 and RPBE reaction probability curves for $(v=0, j=0) \mathrm{H}_{2}$ at normal incidence are compared in Figure 9. The PW91 results are presented for two different treatments of the reaction probability at low energy. ${ }^{119}$ At room temperature, the RPBE rate constant is more than an order of magnitude lower than the PW91 rate constants.

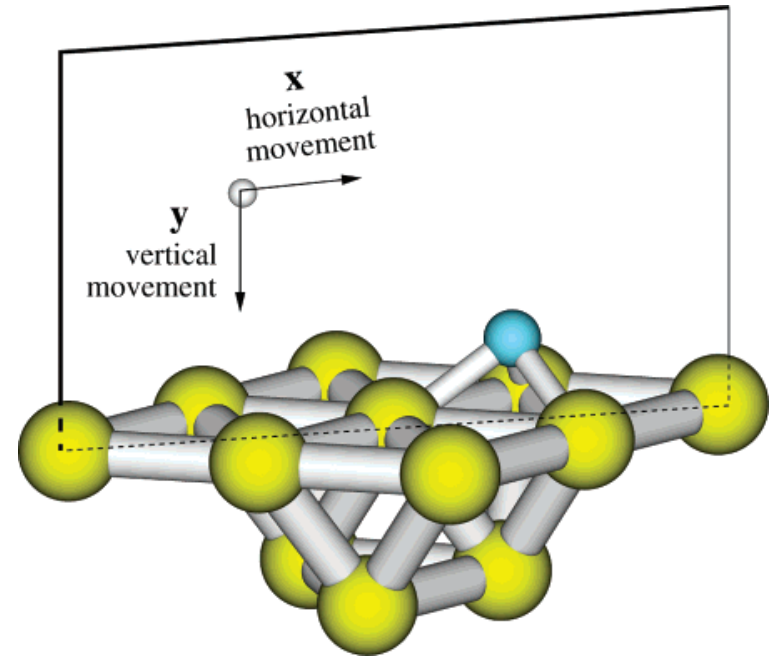

Figure 10. Cluster of $12 \mathrm{Ru}$ atoms to model the reaction $\mathrm{N} *+\mathrm{H} * \rightarrow$ $\mathrm{NH} *+*$. The plane which defines the 2D PES is shown.

At higher temperatures, for example, $750 \mathrm{~K}$ (a temperature that is in the range relevant to modern industrial ammonia production), the PW91 rate constant is only about a factor of 5 larger than the RPBE rate constant. Thus, the rate constants computed for $\mathrm{H}_{2}$ dissociation on clean metal surfaces from PESs based on DFT are considerably affected by uncertainties inherent in DFT and connected with the choice of still imperfect GGAs. However, as the present results show, fortunately the resulting uncertainty in the rate constant can be less than an order of magnitude at temperatures relevant to heterogeneous catalysis (see in Figure 8 how reaction probabilities are weighted at 750 $\mathrm{K})$. These results suggest that further research is warranted on the applicability of current DFT functionals for studies on dissociative chemisorption reactions as well as on the development of improved functionals.

\section{Hydrogenation of Reaction Intermediates, $\mathbf{N H}_{x}$}

It is well-known that after dissociative adsorption of $\mathrm{H}_{2}$ and $\mathrm{N}_{2}$, the next steps in ammonia synthesis are single hydrogenation steps of $\mathrm{N}, \mathrm{NH}$, and $\mathrm{NH}_{2}$. Due to the involvement of hydrogen in these reactions, one expects that quantum effects influence the associated reaction rates. The energy barriers for the hydrogenation were shown to be quite insensitive to the geometry of the Ru substrate (terrace or step) and to be rather high (more than $1 \mathrm{eV}$ for every single step). ${ }^{44,131}$ Therefore, to keep the calculations feasible, we chose to investigate the quantum tunneling dynamics of the reactions on terrace sites only. To determine the dynamics of the specific steps, we calculated zero-point-corrected reduced dimensionality PESs. On these surfaces, reaction rates were determined by different methods, that is, TST including quantum tunneling corrections ${ }^{132}$ and time-independent scattering theory. ${ }^{133}$

The first hydrogenation step $(\mathrm{H} *+\mathrm{N} * \rightarrow \mathrm{NH} *+*)$ was investigated very thoroughly as a model system for the following steps. ${ }^{134,135}$ The PES was developed on a model cluster consisting of $12 \mathrm{Ru}$ atoms (9 atoms resemble the surface layer and 3 atoms model the second layer); see Figure 10. The cluster size effects were investigated extensively, and it was found that the second layer atoms are necessary to reproduce the correct geometries of the stationary points. However, the accuracy of the cluster models is discussed elsewhere. ${ }^{135}$ For electronic structure calculations, the hybrid DFT (B3LYP) method together with a double- $\zeta$ basis was employed (Los Alamos basis sets including effective core potentials were used for $\mathrm{Ru}$, and $\mathrm{N}$ and 


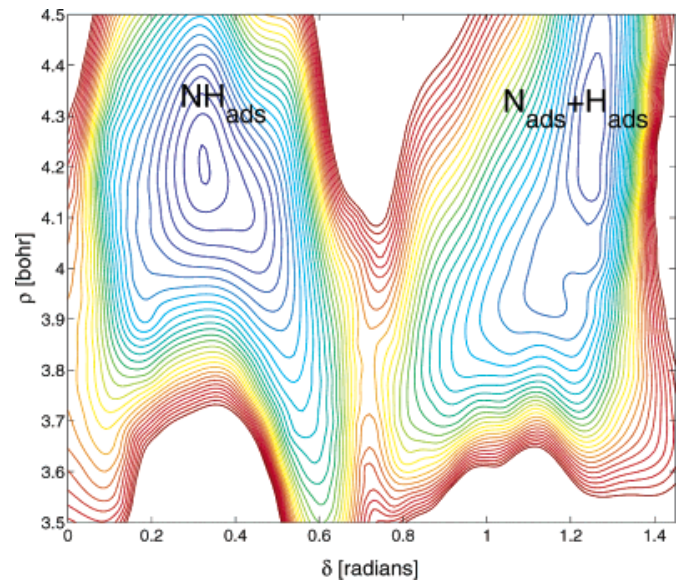

Figure 11. PES in hyperspherical coordinates as it is used for the scattering calculations. Zero-point corrections have been added for all vibrations except the in-plane movement of hydrogen. The equipotential contours are separated by $0.057 \mathrm{eV}$.

$\mathrm{H}$ were described by the $\mathrm{D} 95++(\mathrm{d}, \mathrm{p})$ basis to include diffuse functions). In a recent study, RPBE plane wave results for the $\mathrm{H} *+\mathrm{N} * \rightarrow \mathrm{NH} *+*$ reaction on $\mathrm{Ru}(0001)$ were compared to B3LYP cluster calculations for exactly this model cluster. ${ }^{135} \mathrm{It}$ could be shown that the barriers for reaction are very similar for both methods (deviation of less than $8 \%$ for the forward barrier and $3 \%$ for the backward barrier). The size of the cluster was extensively varied in order to reproduce the experimental adsorption geometries and the experimental vibrations. Again, both the plane wave derived vibrations and the cluster calculations agree very well (less than $1 \%$ difference for the $\mathrm{N}-\mathrm{H}$ stretch of adsorbed $\mathrm{NH}$ and $4 \%$ for the surface-adsorbate stretch) and reproduce experimental findings reasonably well.

The dimensionality of the PES is chosen in such a way that the full 6D minimum energy path (MEP) is entirely included. It is found that, along the MEP, the hydrogen atom just moves in a plane, which is spanned by a vector pointing normal from the Ru surface and a vector directly connecting the reactants $\mathrm{N}$ and $\mathrm{H}$ by a straight line. Thus, a 2D PES was derived from 139 first-principles energy points, where the hydrogen was fixed in the 2D plane and nitrogen was allowed to relax; see Figure 11. At every point, second derivatives had to be calculated to include all other remaining degrees of freedom (i.e., $\mathrm{N}$ movements and $\mathrm{H}$ movement out of the described plane) by their zero-point energy. Throughout the calculation, the $\mathrm{Ru}$ atoms were kept fixed on their experimental values to keep calculations feasible and the gained energies were interpolated by cubic splines.

To make the derived PES useful for further rate calculations, it has to be shifted, rotated, and transformed into hyperspherical coordinates. The Hamiltonian has to follow these coordinate transformations as well. Time-independent scattering calculations were performed on the zero-point-corrected PES in hyperspherical coordinates with the R-matrix method to solve the close coupling equations. ${ }^{133,136}$ From the R-matrix, the scattering matrix may be calculated, and due to the assumption of a high density of states on a transition metal surface, the reaction rate could be calculated using standard rate expressions. ${ }^{134}$ Although the R-matrix method was usually used to describe gas-phase reactions including asymptotic regions, it could be generalized to transition metal surfaces.

Comparison with another method to calculate the rate constant (small curvature tunneling ${ }^{132}$ ) shows good agreement with the rates derived by scattering theory. One advantage of the scattering method is that state selected reaction rates are available. It also shows that at ambient temperatures the reaction

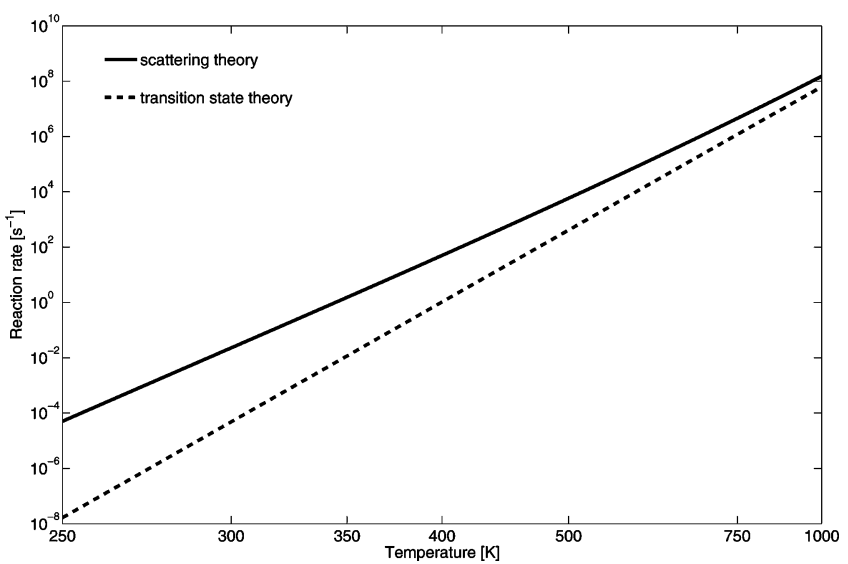

Figure 12. Reaction rates for $\mathrm{N} *+\mathrm{H} * \rightarrow \mathrm{NH} *+*$ on $\mathrm{Ru}(0001)$ by scattering and transition state theory.

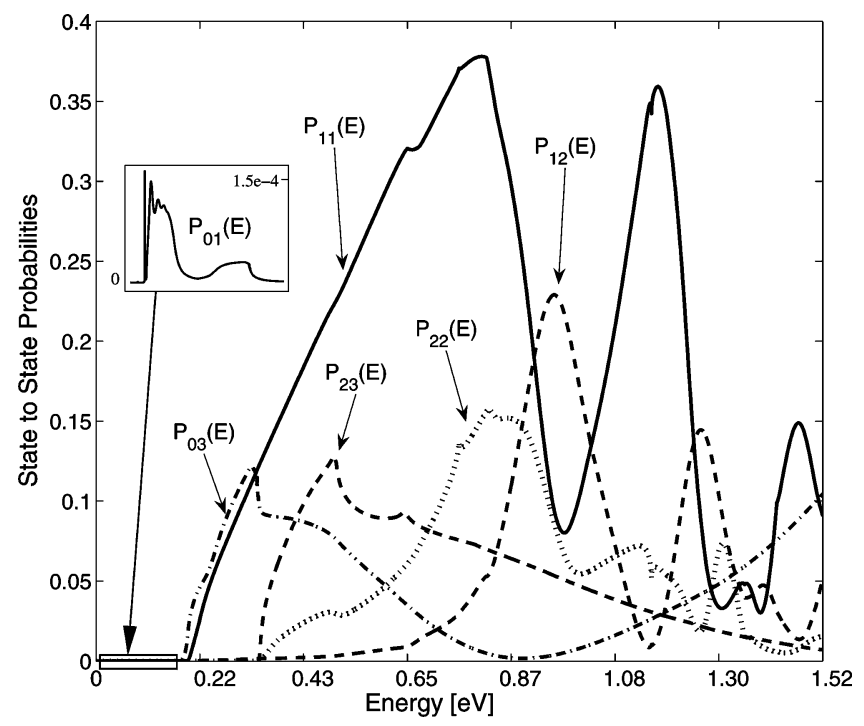

Figure 13. State-to-state reaction probabilities for the formation reaction of $\mathrm{NH}$ on a $\mathrm{Ru}(0001)$ surface. $P_{n m}$ denotes the reaction probability from the $n$th excited state of the reactant into the $m$ th excited state of the product.

$(\mathrm{H} *+\mathrm{N} * \rightarrow \mathrm{NH} *+*)$ proceeds from the ground state of the reactants to low excited states of the products. Only at quite high temperatures the reaction may also proceed from excited states of reactant. Quantum tunneling was shown to have some impact on the reaction rates, especially at room temperature where it enhances the reaction by a factor of 70; see Figure 12. At higher temperatures, as expected, the influence of quantum tunneling decreases, implying a low impact of quantum tunneling at current catalytic temperatures. Figure 13 displays the state selected reaction probabilities which significantly contribute to the reaction rate. Reactions from the ground state of the reactants preferably proceed into the first or third excited state of the products. Contributions from reactions from excited states are expected at higher temperatures and will end up in vibrationally hot products.

The next steps in ammonia synthesis are the hydrogenations of $\mathrm{NH}$ and $\mathrm{NH}_{2}$. In these cases, at least 3D PESs have to be derived, as the MEP is not restricted to a plane anymore. However, the methods established for the first hydrogenation step can also be applied to higher dimensional PESs. Preliminary results show again a low impact of tunneling on the reaction rates of the hydrogenation steps, at least under industrial conditions. 
Although the energy barriers for the hydrogenation steps within the ammonia synthesis are quite high, they are not the rate-limiting step of the process $;{ }^{44,45}$ see the introduction part. Close investigation of these reactions reveals that quantum tunneling enhances the reaction rate slightly and lowers the apparent activation energy of these processes, whereas the ratelimiting step itself $\left(\mathrm{N}_{2}\right.$ dissociation) does not display any quantum tunneling contributions; see section III.

Quantum effects for rate calculations were shown to be essential when describing the single hydrogenation steps within ammonia synthesis. The use of transition state theory (without tunneling corrections) underestimates the reaction rates up to several orders of magnitude at lower temperatures. Therefore, accurate reaction rate calculations have to be performed. Here, the R-matrix method to solve the close coupling equations was extended to PESs derived on transition metal surfaces. The stepwise hydrogenation from $\mathrm{N}$ to $\mathrm{NH}_{3}$ on a ruthenium cluster was investigated, and first-principles rate constants were derived. Tunneling enhances the reaction rate and cannot be neglected at lower temperatures. However, under industrial conditions, it makes an insignificant difference.

Scattering theory also provides state selected rate constants from which the most important transitions during the reactions can be deduced. State selectivity information may help in designing a reaction control via specific excitation of reaction enhancing modes on various kinds of surface reactions. This would be the next important step in understanding and controlling heterogeneous catalysis.

\section{Ammonia Kinetics from First-Principles Calculations}

A complete characterization of a catalytic reaction, based solely on first principles, has been a long-lasting dream in the surface science and catalysis communities. From the literature, one finds several publications where this dream has been pursued. For instance, Linic et. al. ${ }^{13}$ put forth a DFT-based mean-field kinetic model for the selective oxidation of ethylene on Ag catalyst, which reproduces experimental data with an overall good agreement. One step further was taken by Reuter and co-workers. ${ }^{19}$ They used a DFT-based kinetic Monte Carlo description for the $\mathrm{CO}$ oxidation on a single-crystal $\mathrm{RuO}_{2}(110)$ surface. Although both examples are impressive achievements, a complete first-principles description of a catalytic reaction over a real catalyst under industrial conditions requires a further step. Such a step includes moving beyond perfect single-crystal surfaces, including lateral interactions, and treating the full complexity of nanosize catalyst particles.

For ammonia synthesis, DFT calculations were used to quantitatively outline the complete reaction mechanism including all elementary reaction steps. ${ }^{44} \mathrm{~N}_{2}$ dissociation was found to take place at defects and steps, preferentially at sites with a $\mathrm{B}_{5}{ }^{137,138}$ configuration. These results, further strengthened by the findings discussed in sections III $-\mathrm{V}$, made it possible to construct a first-principles kinetic model for ammonia synthesis. We will present a brief summary of the model below. For more details, see refs 103 and 139.

All of the necessary input parameters of the model such as adsorption energies, vibrational frequencies, interactions, and activation barriers were calculated with the DFT code DACAPO. ${ }^{116}$ For details concerning the values of the above quantities, see ref 103.

According to DFT calculations, the height of the activation barrier for $\mathrm{N}_{2}$ dissociation on the flat $\mathrm{Ru}(0001)$ surface is 1.9 $\mathrm{eV}$, whereas on a $\mathrm{Ru}$ step at a $\mathrm{B}_{5}$ site it is $0.49 \mathrm{eV}$. From the interplay between DFT calculations and experiments, ${ }^{56}$ it was

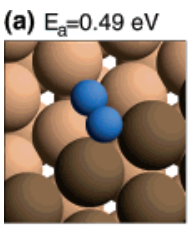

(e) $E_{a}=0.67 \mathrm{eV}$

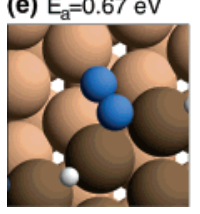

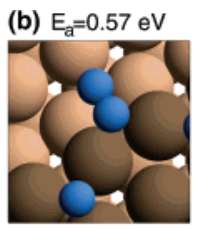

(f) $E_{a}=0.71 \mathrm{eV}$

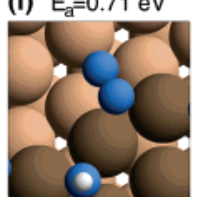

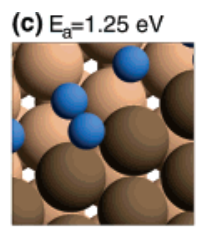

(g) $E_{a}=1.06 \mathrm{eV}$

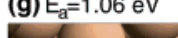

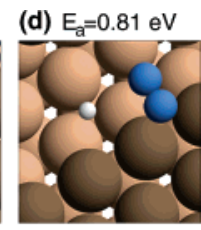

(h) $\mathrm{E}_{\mathrm{a}}=0.99 \mathrm{eV}$

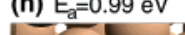

Figure 14. Variation in transition state energy due to the presence of different intermediates. As macroscopic conditions change, that is, the partial pressures of $\mathrm{H}_{2}$ and $\mathrm{NH}_{3}$, in the catalytic reactor, the $\mathrm{N}_{2}$ dissociation will be dominated by different channels. In parts $a-d$, a B5 site with (a) no adsorbates in the neighboring sites, (b) adsorbed $\mathrm{N}$ on the upper step, (c) adsorbed $\mathrm{N}$ on the lower step, and (d) adsorbed $\mathrm{H}$ on the lower step. In parts $\mathrm{e}-\mathrm{h}$, (e) adsorbed $\mathrm{H}$, (f) adsorbed $\mathrm{NH}$, (g) adsorbed $\mathrm{NH}_{2}$ on the upper step, and (h) adsorbed $\mathrm{H}$ both on the upper and on the lower step. The Ru atoms on the upper step are colored dark brown, and on the lower step, they are colored light brown.

shown that step sites dominate $\mathrm{N}_{2}$ dissociation. Using this observation and the fact that $\mathrm{N}_{2}$ dissociation is the rate-limiting step for industrial ammonia synthesis, we constructed a kinetic model that describes the ammonia production at active $\mathrm{B}_{5}$ sites. The calculated potential energy diagram given in Figure 1 presents the energetics of ammonia synthesis at low intermediate coverages. However, in reality, reacting molecules interact with their neighbors, as can be seen from Figure 14, where activation energies for $\mathrm{N}_{2}$ dissociation in the presence of different neighboring intermediates are given.

The contributions from different local environments in Figure 14 are included in the reaction rate equation, which is written as

$$
r\left(T, p_{\mathrm{N}_{2}}, p_{\mathrm{H}_{2}}, p_{\mathrm{NH}_{3}}\right)=(1-\gamma) \sum_{i} P_{i} k_{i} p_{\mathrm{N}_{2}} \theta_{*}
$$

where $T$ is the temperature, $p_{\mathrm{N}_{2}}, p_{\mathrm{H}_{2}}$, and $p_{\mathrm{NH}_{3}}$ are the pressures of $\mathrm{N}_{2}, \mathrm{H}_{2}$, and $\mathrm{NH}_{3}$, respectively, $\theta *$ is the probability to have two empty sites, one on the upper step (US) and one on the lower step (LS), $P_{i}$ is the conditional probability for a certain local environment $i$ given $\theta_{*}, k_{i}$ is the corresponding rate constant, $\gamma=p_{\mathrm{NH}_{3}}{ }^{2} / p_{\mathrm{N}_{2}} p_{\mathrm{H}_{2}}{ }^{3} K_{\mathrm{g}}$ ensures a correct approach to equilibrium, and $K_{\mathrm{g}}$ is the gas-phase equilibrium constant for the total reaction.

We applied Monte Carlo techniques ${ }^{140}$ to ensure that surface coverages and adsorbate-adsorbate correlations were calculated in the correct way. This approach is well suited for the ammonia synthesis, as the rate-determining $\mathrm{N}_{2}$ dissociation implies that the rest of the reaction steps can be considered to be in quasiequilibrium. The equilibrium condition of the grand canonical ensemble includes hydrogenation/dehydrogenation reactions and adsorption/desorption events. The configuration space was sampled using the Metropolis algorithm. The coverage of empty sites, $\theta *$, and the conditional probability, $P(k \mid *)$, which describes the probability of having one particular adsorbate, $k$, next to an empty site, $*$, were determined from the ensemble of configurations obtained in our MC simulation. The conditional probability for a certain local environment, $P_{i}$ (see eq 10), was calculated according to

$$
P_{i}=P\left(k^{\mathrm{US}} \mid *^{\mathrm{US}}\right) P\left(l^{\mathrm{US}} \mid *^{\mathrm{US}}\right) P\left(m^{\mathrm{LS}} \mid *^{\mathrm{LS}}\right) P\left(n^{\mathrm{LS}} \mid *^{\mathrm{LS}}\right)
$$




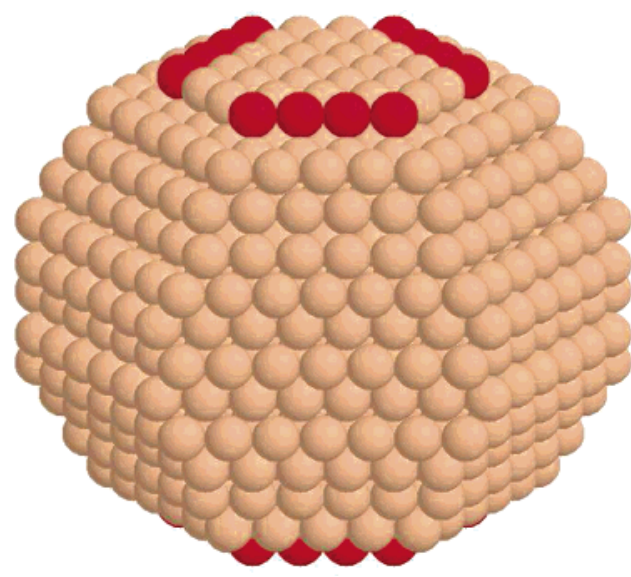

Figure 15. Typical calculated Ru particle with an average diameter of $2.9 \mathrm{~nm}$. B5 sites, colored here in red, are found at the $(0001) /(1011)$ intersection if we include edge effects.

where $k^{\mathrm{US}}, l^{\mathrm{US}}, m^{\mathrm{LS}}$, and $n^{\mathrm{LS}}$ can be any of the adsorbed species $*, \mathrm{H}, \mathrm{N}, \mathrm{NH}, \mathrm{NH}_{2}$, and $\mathrm{NH}_{3}$.

Equation 10 gives the ammonia synthesis rate per active site. What we need next is the average number of active sites, $\rho$, in the catalyst, and it was estimated in the following way. First, we calculated the surface energy of all low-Miller-index $(h+$ $k+l<4) \mathrm{Ru}$ surfaces. ${ }^{103}$ Using these energies, we made a Wulff construction, which gives the equilibrium shape of the crystal, for several $\mathrm{Ru}$ particles with different diameters; see Figure 15. Finally, we integrated the number of active sites per gram of catalyst, obtained from the Wulff constructions, with the particle size distribution and got the estimate for the average number of active sites. The size distribution of the Ru catalyst was obtained from the analysis of high-resolution transmission electron microscope images, and it actually constitutes the only link between the real catalyst and our model.

We modeled a plug-flow reactor by dividing the catalyst bed into $N$ slices and assuming an equal distribution of the catalyst mass. The ammonia production rate is calculated in each slice. The output of the previous slice acts as an input to the next slice. Summing over the rate equation, eq 10, we get the following description for the plug-flow reactor:

$$
\sum_{x=0}^{N} r\left(T, p_{x}\left(\mathrm{~N}_{2}\right), p_{x}\left(\mathrm{H}_{2}\right), p_{x}\left(\mathrm{NH}_{3}\right)\right) \rho m / N \mathrm{~d} x
$$

where $\rho$ is the average number of active sites, $m$ is the catalyst mass, $N$ is the number of slices, $T$ is the temperature, and $p_{x-}$ $\left(\mathrm{N}_{2}\right), p_{x}\left(\mathrm{H}_{2}\right)$, and $p_{x}\left(\mathrm{NH}_{3}\right)$ are the pressure of $\mathrm{N}_{2}, \mathrm{H}_{2}$, and $\mathrm{NH}_{3}$ in slice $x$, respectively. The productivity of ammonia is simply the partial pressure of ammonia at the outlet.

The details of the experimental setup for ammonia productivity measurements are given in ref 103 .

Figure 16 summarizes the main results from our firstprinciples model. The comparison between the calculated and the measured ammonia productivity is given in Figure 16a. The overall theoretical productivity is a factor of 3-20 too small. We also observe that the inhibition by ammonia is slightly too weak. However, given that there are no fitted parameters, the agreement is remarkable. Figure $16 \mathrm{~b}$ presents the local environments that have the largest contribution to the total rate as we integrate through the reactor. Note that it is not the local environment with the lowest activation energy that has the largest contribution to the total rate. That is because the probability to have this particular local environment is very small
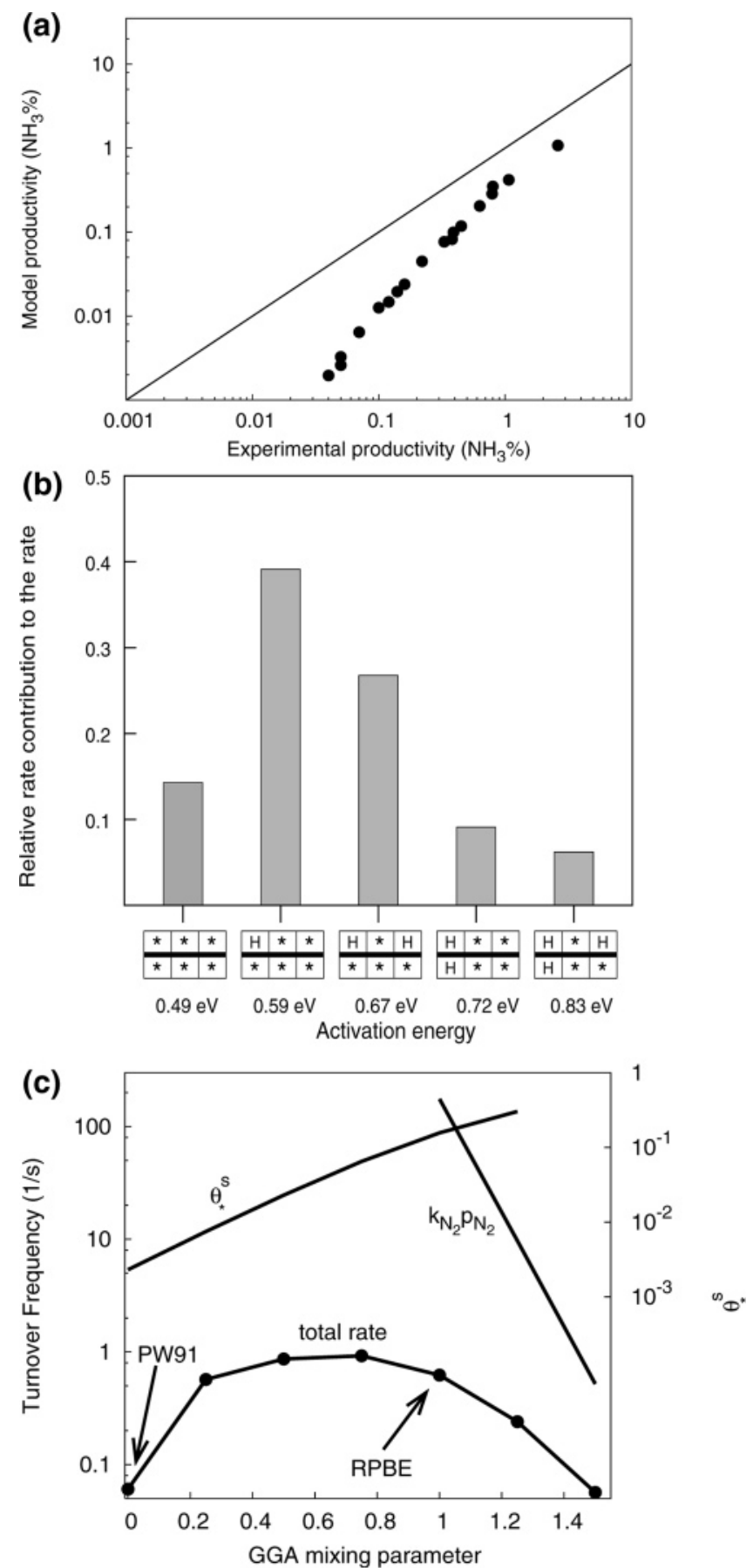

Figure 16. (a) Comparison of the ammonia productivity between the calculated (dots) and the measured (solid line) results. Complete agreement would mean that the dots should follow the diagonal line. The total pressure is 100 bar, $\mathrm{N}_{2} / \mathrm{H}_{2}=1: 3$, and the temperature range is from 320 to $440{ }^{\circ} \mathrm{C}$. (b) The main contributions to the rate per surface site per second (the turnover frequency, TOF) in one slice of the reactor. Below, we use a symbolic representation of the local environment showing the dissociation sites and four neighboring sites on the upper and lower terrace. (c) Dependence of the rate on a parameter, $x$, determining the mixing of results obtained by two different treatments of exchange-correlation effects, the GGA PW91 and RPBE methods. The variation in the rate constant for $\mathrm{N}_{2}$ dissociation, $k_{\mathrm{N}_{2}}$, and the coverage of free sites at the step, $\theta^{\mathrm{US}}$, are also given, showing why large variations in both compensate to give a small variation in the total rate, which is proportional to both $k_{\mathrm{N}_{2}}$ and $\theta^{\mathrm{US}}, \theta^{\text {LS }}$.

under the synthesis conditions. The problem associated with the inherent accuracy of the DFT calculations ${ }^{105}$ is addressed in Figure 16c. For instance, an error in an activation energy of 
$0.25 \mathrm{eV}$, which is not unheard of in DFT, leads to a factor of 148 error in the rate of an elementary reaction at $600 \mathrm{~K}$. Hence, we tested how sensitive our model is to the accuracy of the DFT calculations. One systematic way to do this is to calculate all energies with two different approximations for exchange and correlation functionals. In this work, we used the RPBE ${ }^{105}$ and PW9 $1^{104}$ functionals. We then interpolated all of the energies between the two functionals according to $E(x)=x E_{\mathrm{RPBE}}+(1$ $-x) E_{\mathrm{PW} 91}$ and calculated the rate with various degrees of mixing of the two functionals. As seen in Figure 16c, the rate depends only weakly on the mixing parameter, $x$. Therefore, the total reaction rate is considerably less sensitive to the absolute error than the rate of each individual reaction step.

The reason for this behavior is the so-called compensation effect. ${ }^{114}$ It means that the barrier for dissociation and the stability of intermediates on the surface vary together and therefore a change in overall interaction strength has only a small effect on the net rate. Going from RPBE to PW91, the barrier for $\mathrm{N}_{2}$ dissociation decreases substantially (by $0.6 \mathrm{eV}$ ), making this process much faster. The dissociative chemisorption energy of $\mathrm{H}_{2}$ changes simultaneously from 0.36 to $0.52 \mathrm{eV}$, and the $\mathrm{N}_{2}$ chemisorption energy changes from 0.8 to $1.4 \mathrm{eV}$. This increases the coverage (through the equilibrium with $\mathrm{H}_{2}$ and $\mathrm{NH}_{3}$ in the gas phase), thus decreasing the number of free sites for dissociation. It is the compensation between two opposite trends that gives rise to a volcano in the catalytic activity as a function of the bond strength. ${ }^{114}$ The best catalysts are found near the top of the volcano, and for them, the compensation effect is the largest. Since such collinear variations in activation energies and bond strengths are found quite generally, we would expect compensation effects to be found in a large number of cases.

If the remaining discrepancy seen in Figure 16a originates from the used xc functional, it must be due to relative errors in adsorption energies between different adsorbates. To test this, we decreased the adsorption energy of $\mathrm{H}$ atoms by $0.06 \mathrm{eV}$ compared to the $\mathrm{NH}_{x}$ species. In turn, this leads to a complete agreement between the calculated and measured $\mathrm{NH}_{3}$ productivities. ${ }^{103}$ Thus, small relative errors are the most likely reason the calculated rate is underestimated in Figure 16a.

We conclude that it is possible to predict the productivity of a complete catalytic reaction under industrial conditions within a factor of 3-20 on the basis of DFT calculations. It is shown that the good agreement can be associated with the fact that the total rate of a network of reactions is less sensitive to systematic inaccuracies in the calculated energies than the rate of the individual elementary reaction steps. This offers hope for computer-based methods in the search for new catalysts.

\section{Biomimetic Ammonia Synthesis}

It is clear that a modern implementation of the Haber-Bosch process provides a highly efficient method for producing ammonia in large quantities. The process is normally carried out in an integrated plant with hydrogen production (by, e.g., steam reforming followed by the water-gas shift reaction), and then, a subsequent $\mathrm{CO} / \mathrm{CO}_{2}$ cleanup step (by, e.g., the methanation reaction) before the actual Haber-Bosch process is performed. This way the energy released during the exothermic ammonia synthesis can by heat exchange be canalized back into the production of hydrogen, which is the energy-intensive step. The integration of several large processes together with the highpressure conditions (150-200 bar) for the Haber-Bosch process means that the global ammonia production is carried out in a few hundred centralized plants. One could imagine several scenarios, where it would be advantageous to produce ammonia locally on a smaller scale, even if the production costs could not match the Haber-Bosch process. This point of view is not becoming less relevant as ammonia is used in the selective catalytic reduction (SCR) process for removing nitrogen oxides from diesel engine exhaust, with the recent proposal of using ammonia salts as an energy carrier, ${ }^{141}$ or with the increased political focus on transporting safety for hazardous chemicals. Additionally, an undesired feature of the Haber-Bosch process is that the equilibrium of the reaction is driven somewhat too far toward the reactants due to the high reaction temperature necessary for fast kinetics. This means that most of the $\mathrm{N}_{2}$ and $\mathrm{H}_{2}$ goes unreacted through the reactor bed, and has to be recycled after being cleaned for ammonia.

We have performed a theoretical study of the possibility of producing ammonia under ambient temperatures and pressures. As mentioned in the Introduction, microorganisms exist in nature which use the enzyme nitrogenase to produce ammonia from protons, electrons, and atmospheric nitrogen. In the enzyme, there is an active site, a $\mathrm{MoFe}_{7} \mathrm{~S}_{9}$ cluster, which catalyzes the reaction

$$
\mathrm{N}_{2}+8 \mathrm{H}^{+}+8 \mathrm{e}^{-} \rightleftharpoons 2 \mathrm{NH}_{3}+\mathrm{H}_{2}
$$

The source of energy for this reaction consists of at least 16 ATP molecules. ${ }^{4,5}$ These presumably increase the chemical potential of the electrons. It has been hypothesized that one part of the enzyme functions just like a battery. ${ }^{142}$

The reaction mechanisms in the industrial and the enzymatic synthesis differ significantly. In the enzyme, $\mathrm{N}_{2}$ molecules are hydrogenated, ${ }^{60}$ while, in the Haber-Bosch method, the strong $\mathrm{N}_{2}$ triple bonds as well as the $\mathrm{H}_{2}$ bonds are cleaved before nitrogen and hydrogen atoms on the metal surface can react, so in this case, it is the $\mathrm{N}$ atoms which are hydrogenated. It appears to be a very reasonable starting point in the search for a lowtemperature/low-pressure ammonia synthesis process to attempt to mimic the biological mechanism. According to the current understanding of the biological mechanism, this would imply looking for an electrochemically activated process following the direct $\mathrm{N}_{2}$ hydrogenation route.

To facilitate the theoretical study of such processes, we thus need to extend the scope of standard surface slab DFT calculations to what a priori appears to be rather complicated electrochemical reactions. The electrochemical processes depend on proton transfers, electric field effects, electrical bias, $\mathrm{pH}$ values, solvation, and ionic transport properties. Whereas such a calculation could perhaps be feasible using a modern electron transport program representing a very small electrochemical cell, there is a definite advantage in decomposing the problem and analyzing the separate contributions. This not only gives a better understanding of the given electrochemical problem but also makes it possible to perform calculations on many different systems already with presently available computer power. We have found ${ }^{143}$ that, if we are only concerned with the stability of reaction intermediates, standard DFT calculations can relatively easily be corrected to provide useful insight into electrochemical reactions. With such a post-treatment of the DFT calculations, one can surprisingly accurately reproduce the thermochemistry of electrochemical reactions. The method does not reveal how to describe the voltage dependence of a given reaction barrier, if this barrier lies higher than both its initial and final states. ${ }^{143,144}$ However, many electrochemical reactions proceed without such additional barriers. For example, for protonation reactions, it appears that the only present energy barriers are due to differences in the free energy between the 


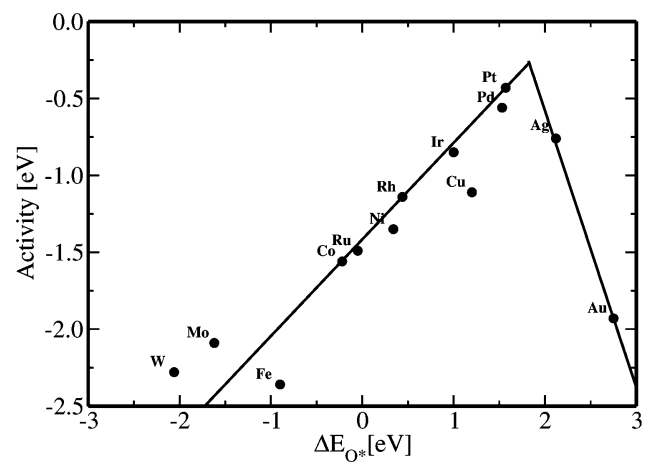

Figure 17. Trend in oxygen reduction activity plotted as a function of the oxygen binding energy.

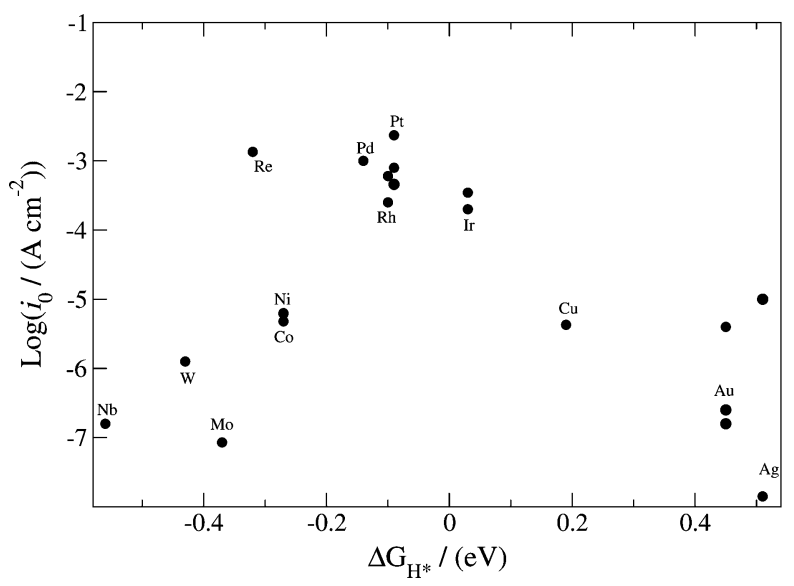

Figure 18. Experimentally observed hydrogen exchange currents for a range of metal surfaces. The measured exchange currents which are taken from the literature (see ref 144 for details) show a volcano relation when plotted against a descriptor deduced from the presented methodology.

initial and final states. Using the suggested methodology ${ }^{143}$ on the oxygen reduction reaction, one can thus understand in detail why Pt is the best fuel cell cathode material among the pure metals, as a simple microkinetic model based on the presented methodology correctly describes the activity trend for most of the pure transition metals ${ }^{143}$ (see Figure 17). A model for hydrogen evolution also based on the methodology outlined here was used to correctly reproduce the experimentally observed trends in hydrogen exchange current ${ }^{144}$ (see Figure 18).

Since protonation reactions in particular appear to be so welldescribed within the methodology, there is hope that it is adequate for also describing electrochemical ammonia synthesis. On a ruthenium electrode in aqueous solution in an electrochemical cell, ammonia synthesis by the same reaction mechanism as that in the Haber-Bosch process is excluded because any available ruthenium step sites for $\mathrm{N}_{2}$ dissociation will be poisoned by strongly adsorbing oxygen atoms and $\mathrm{OH}$ groups. The $\mathrm{N}_{2}$ dissociation has too high of a barrier to take place on the close-packed terraces at such low temperature. This leaves the biomimetic mechanism strongly favored, especially because the tendency for direct protonation of the nitrogen molecule can be tuned directly by varying the voltage over the electrochemical cell. In Figure 19, ${ }^{145}$ we show the full free energy reaction diagram for the biomimetic ammonia synthesis route at zero potential with respect to the standard hydrogen electrode. It is observed that the first hydrogenation process has by far the highest barrier. An energy diagram is also shown at a potential of $-1.08 \mathrm{~V}$. At

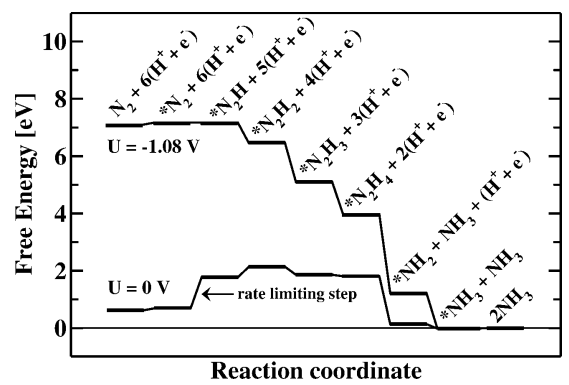

Figure 19. Free energy diagram for the biomimetic ammonia synthesis reaction. The potential of $-1.08 \mathrm{~V}$ is the potential below which all protonation reactions occur spontaneously.

such a low potential, all protonation reactions proceed without barriers according to the assumption just mentioned. If we were to apply such a negative potential, ammonia would be produced electrochemically. There is, however, a significant problem. At much less negative potentials, the ruthenium electrode will begin to catalyze hydrogen evolution. ${ }^{145}$ At potentials as low as $-1.08 \mathrm{~V}$, the hydrogen evolution will strongly dominate the production of ammonia and therefore render the approach useless. To enable electrochemical ammonia synthesis, one would therefore have to find a way to inhibit the simultaneous hydrogen evolution. ${ }^{145}$

We conclude that the thermochemistry of electrochemical reactions can be approximately described by density functional theory calculations by following a simple set of rules. Such calculations show that electrochemical synthesis of ammonia is in principle possible on the close-packed surface of ruthenium but also that the necessary potential is unfortunately well into the hydrogen evolution regime of the electrochemical cell.

\section{Discussion and Overall Conclusions}

As indicated in the Introduction, ammonia synthesis is the most well-characterized heterogeneous catalytic reaction of today. The present knowledge reflects the accumulated effort of more than a century of scientific studies. Hence, already at the beginning of this collaborative work, we were quite confident that we would indeed be able to predict catalysis and understand ammonia synthesis from first-principles calculations. Below, the main results and insights are summarized.

Our study on ammonia gas-phase chemistry indicates that the gas-phase ammonia formation favors pathways that travel through radical states accessible only under extreme conditions. This explains why ammonia, can be produced in nature in lightning storms where radicals are likely to be present.

Thermally activated ammonia synthesis at solid surfaces involves six elementary reactions (eqs $1-6$ ). We have shown the following: (i) Quantum tunneling corrections for $\mathrm{N}_{2}$ dissociation are negligible at all temperatures relevant to industrial synthesis conditions. Thus, classical harmonic TST forms a reliable basis to study $\mathrm{N}_{2}$ dissociation from first principles. (ii) The rate for $\mathrm{H}_{2}$ dissociation is found to be high at all relevant temperatures; thus, this process can be safely assumed to be in quasi-equilibrium with the gas phase. (iii) The hydrogenation steps, eqs $3-6$, are found to be only slightly enhanced by quantum tunneling (however, at room temperature it can play a significant role), further strengthening the role of $\mathrm{N}_{2}$ dissociation as the rate-determining step at industrially relevant temperatures, even though some hydrogenation steps have higher barriers relative to the transient reactants.

We performed a full-scale DFT mapping of adsorption energies and interactions of the different reaction intermediates 
in ammonia synthesis. On top of this, we constructed a kinetic model that is able to predict the ammonia productivity within a factor of 3-20 for an industrially relevant catalyst. Even if the results shown here are encouraging, the most important finding of our study is how insensitive the model is to the choice of exchange-correlation functional. As such, it offers real hope that in general DFT calculations can provide an overall good description of catalytic reactions.

Finally, we also discuss a biomimetic way of ammonia production. A promising route to a local small-scale production under normal pressure conditions by use of electrochemical synthesis methods is indicated.

\section{Outlook}

We have shown that the ammonia synthesis reaction can be understood in atomic-scale detail directly by the application of various levels of quantum-mechanics-based electronic structure calculations. The theoretical study of such an experimentally well-characterized system is an excellent starting point for testing which level of theory is necessary for describing the reaction with sufficient accuracy.

Whereas theoretical developments often take years to be achieved, and even though electronic structure calculations still do not scale too well with system size, it appears that we are now very close to a breakthrough for the use of theoretical modeling in the field of catalyst design. The fact that we can now treat one reaction on one surface in such enormous theoretical detail reveals promise. There is so to say a linear correspondence between the computational power and the number of materials we could screen as catalysts for the given reaction at the current high level of accuracy. With the historical increase in available computer power, it is difficult to remain skeptical of the importance of theory in the field of catalysisalready in the near future. It can be envisioned that soon theoretical modeling will not only be used for reproducing the experimentally known facts about a given reaction on a given surface but could become the standard choice as the first starting point when a new catalyst for a known reaction is desired, or even when an unknown reaction to obtain a given product is needed. This would be the beginning of the era of "catalysis informatics".

However, for this era to arrive, some developments are still necessary. These are perhaps less related to further developments of the quantum simulations and statistical mechanical methods we have employed in this paper and more related to the automatization and integration of our methods. Clearly, if we want to be able to theoretically screen a large number of materials, it would be a daunting task having to go into the level of detail presented in this paper for each single material. Hopefully, generalizations are possible so that the level of detail can be decreased, and automatization may be feasible so that the necessary man power can be limited. We believe that the detailed analysis presented in this paper will provide an important stepping stone in this direction.

Acknowledgment. We thank the EU for financial support of the Research Training Network "Predicting Catalysis" (Contract No. HPRN-CT-2002-00170). In addition, economic support from the Deutsche Forschungsgemeinschaft, the Fond der Chemischen Industrie, and the Danish Research Agency, through Grant No. 26-04-0047, and the Fundação para a Ciência e Tecnologia (program PRAXIS XXI) is also acknowledged. We thank Mr. Luis A. Poveda, Dr. Ernst Pijper, Dr. Mark Somers, Prof. Bjørk Hammer, and Dr. Alessandro Volpi for useful discussions, Poul Møller and Sussie Nygaard Larsen for assistance with the cover art, and we thank NCF/NWO, WCSS, and DCSC for computer resources.

\section{References and Notes}

(1) Smil, V. Nature 1999, 400, 415.

(2) Ullmann's Encyclopedia of Industrial Chemistry, 7th ed.; John Wiley \& Sons: Weinheim, 2005.

(3) Tamaru, K. In Catalytic Ammonia Synthesis, Fundamentals and Practice; Jennings, J. R., Ed.; Plenum Press: New York, 1991; p 1.

(4) Stryer, L. Biochemistry, 4th ed.; W.H. Freeman: New York, 1995

(5) Burgess, B. K.; Lowe, D. J. Chem. Rev. 1996, 96, 2983-3012.

(6) Schlögl, R. Angew. Chem., Int. Ed. 2003, 42, 2004.

(7) Boudart, M. Top. Catal. 1994, 1, 405.

(8) Jennings, J. R., Ed. Catalytic Ammonia Synthesis: Fundamentals and Practice; Plenum Press: New York, 1994.

(9) Grunze, M. In The Chemistry and Physics of Solid Surfaces and Hetrogeneous Catalysis; King, D. A., Woodruff, D. P., Eds.; Elsevier: Amsterdam, The Netherlands, 1982; Vol. 4.

(10) Nielsen, A., Ed. Ammonia: Catalysis and Manufacture; Springer: New York, 1995.

(11) Neurock, M.; van Santen, R. A. J. Phys. Chem. B 2000, 104, 11127-11145.

(12) Bocquet, M.; Michaelides, A.; Loffreda, D.; Sautet, P.; Alavi, A.; King, D. A. J. Am. Chem. Soc. 2003, 125, 5620-5621.

(13) Linic, S.; Barteau, M. A. J. Am. Chem. Soc. 2003, 125, 4034.

(14) Linic, S.; Barteau, M. A. J. Catal. 2003, 214, 200-212.

(15) Hammer, B. J. Catal. 2001, 199, 171-176.

(16) Eichler, A.; Hafner, J. J. Catal. 2001, 204, 118-128.

(17) Anstrom, M.; Topsøe, N.; Dumesic, J. A. J. Catal 2003, 213, 115125 .

(18) Sierka, M.; Sauer, J. J. Phys. Chem. B 2001, 105, 1603-1613.

(19) Reuter, K.; Frenkel, D.; Scheffler, M. Phys. Rev. Lett. 2004, 93 116105 .

(20) Remediakis, I. N.; Lopez, N.; Nørskov, J. K. Angew. Chem., Int. Ed. 2005, 44, 1824-1826.

(21) Haber, F. Nobel Prize Lecture 1918. Nobel Lectures, Chemistry 1901-1921; Elsevier: Amsterdam, The Netherlands, 1966.

(22) Bosch, F. Nobel Prize Lecture 1931. Nobel Lectures, Chemistry 1922-1941; Elsevier: Amsterdam, The Netherlands, 1966.

(23) Haber, F.; van Oordt, G. Z. Anorg. Chem. 1905, 44, 341.

(24) Mittasch, A. Adv. Catal. 1950, 2, 81-104.

(25) Mittasch, A. U.S. Patent 1,173,532, 1913.

(26) Aika, K.; Hori, H.; Ozaki, A. J. Catal 1972, 27, 424-431.

(27) Ozaki, A.; Aika, K.; Furuta, A.; Okagami, A. U.S. Patent 3,770,658, 1973.

(28) Ozaki, A.; Aika, K. In Catalysis, Science and Technology; Anderson J. R., Boudart, M., Eds.; Springer: Berlin, 1981.

(29) Aika, K.; Ozaki, O. In Ammonia: Catalysis and Manufacture; Nielsen, A., Ed.; Springer: New York, 1995.

(30) Dahl, S.; Logadottir, A.; Jacobsen, C. J. H.; Nørskov, J. K. Appl. Catal., A Gen. 2001, 222, 19-29.

(31) Logadottir, A.; Rod, T. H.; Nørskov, J. K.; Hammer, B.; Dahl, S.; Jacobsen, C. J. H. J. Catal. 2001, 197, 229-231.

(32) Jacobsen, C. J. H.; Dahl, S.; Clausen, B. S.; Bahn, S.; Logadottir, A.; Nørskov, J. K. J. Am. Chem. Soc. 2001, 123, 8404.

(33) Boisen, A.; Dahl, S.; Nørskov, J. K.; Christensen, C. H. J. Catal. 2005, 230, 309-312.

(34) Foster, A. I.; James, P. G.; McCarroll, J. J.; Tennison, S. R. U.S. Patent, 4,163,775, 1979.

(35) McCarroll, J. J.; Tennison, S. R.; Wilkinson, N. P. U.S. Patent, 4,600,571, 1986.

(36) Chementator Chem. Eng. 1993, 100, 19

(37) Emmett, P. H.; Brunauer, S. J. Am. Chem. Soc. 1933, 55, 1738.

(38) Emmett, P. H.; Brunauer, S. J. Am. Chem. Soc. 1934, 56, 35.

(39) Boszo, F.; Ertl, G.; Grunze, M.; Weiss, M. J. Catal. 1977, 49, 391.

(40) Ertl, G.; Weiss, M.; Lee, S. B. Chem. Phys. Lett. 1979, 60, 391.

(41) Paal, Z.; Ertl, G.; Lee, S. B. Appl. Surf. Sci. 1981, 8, 231.

(42) Ertl, G.; Lee, S. B.; Weiss, M. Surf. Sci. 1982, 114, 527.

(43) Ertl, G. J. Vac. Sci. Technol., A 1983, 1, 1247.

(44) Logadottir, A.; Nørskov, J. K. J. Catal. 2003, 220, 273.

(45) Bligaard, T.; Nørskov, J. K.; Dahl, S.; Matthiesen, J.; Christensen,

C. H.; Sehested, J. J. Catal. 2004, 224, 206-217.

(46) Campbell, C. T. J. Catal. 2001, 204, 520-524.

(47) Dumesic, J. A. J. Catal. 1999, 185, 496.

(48) Spencer, N. D.; Schoonmaker, R. C.; Somorjai, G. A. J. Catal. 1982, 74, 129.

(49) Strongin, D. R.; Carrazza, J.; Bare, S. R.; Somorjai, G. A. J. Catal.

1987, 103, 213.

(50) Strongin, D. R.; Somorjai, G. A. J. Catal. 1988, 109, 51.

(51) Stoltze, P.; Nørskov, J. K. Phys. Rev. Lett. 1985, 55, 2502. 
(52) Dumesic, J. A.; Triviño, A. A. J. Catal. 1989, 116, 119.

(53) Bowker, M. Top. Catal. 1994, 1, 165.

(54) Sehested, J.; Jacobsen, C. J. H.; Törnqvist, E.; Rokni, S.; Stoltze, P. J. Catal. 1999, 188, 83.

(55) Dahl, S.; Törnqvist, E.; Jacobsen, C. J. H. J. Catal. 2001, 198, 97. (56) Dahl, S.; Logadottir, A.; Egeberg, R. C.; Larsen, J. H.; Törnqvist, E.; Chorkendorff, I.; Nørskov, J. K. Phys. Rev. Lett. 1999, 83, 1814. (57) Jacobsen, C. J. H.; Brorson, M.; Sehested, J.; Teunissen, H. U.S Patent 6,235,676, 2000 (EP 1036592 A2 Priority Mar 15, 1999).

(58) Kojima, R.; Aika, K. Chem. Lett. 2000, 514.

(59) Jacobsen, C. J. H. Chem. Commun. 2000, 12, 1057

(60) Rod, T. H.; Hammer, B.; Nørskov, J. K. Phys. Rev. Lett. 1999, 82, $4054-4057$. 2874.

(61) Hwang, D.-Y.; Mebel, A. M.; J. Phys. Chem. A 2003, 107, 2865-

(62) Varandas, A. J. C. Adv. Chem. Phys. 1988, 74, 255. Idem. In Conical Intersections: Electronic Structure, Spectroscopy and Dynamics, Advanced Series in Physical Chemistry; Domcke, W., Yarkony, D. R., Köppel, H., Eds.; World Scientific: Singapore, 2004; Chapter 5.

(63) Poveda, L. A.; Varandas, A. J. C. J. Phys. Chem. A 2003, 107, $7923-7930$.

(64) Varandas, A. J. C.; Poveda, L. A. Theor. Chem. Acc., available on web, DOI: $10.1007 / 500214-006-0092-6$.

(65) Poveda, L. A.; Varandas, A. J. C. Phys. Chem. Chem. Phys. 2005, 7, 2867-2873.

(66) Varandas, A. J. C.; Yu, H. G. Mol. Phys. 1997, 91, 301-318.

(67) Ballester, M. Y.; Varandas, A. J. C. Phys. Chem. Chem. Phys. 2005 $11,2305-2317$.

(68) Varandas, A. J. C.; Zhang, L. Chem. Phys. Lett. 2000, 331, 474482.

(69) Varandas, A. J. C.; Zhang, L. Chem. Phys. Lett. 2004, 385, 409416. 5814

(71) Dunning, T. H. J. Chem. Phys. 1989, 90, 1007-1023.

(72) Kendall, R.; Dunning, T., Jr.; Harrison, R. J. Chem. Phys. 1992 $96,6769-6806$.

(73) Knowles, P. J.; Werner, H.-J. Chem. Phys. Lett. 1985, 115, 259267.

(74) MOLPRO is a package of ab initio programs written by Werner, H.-J.; Knowles, P. J. with contributions from Amos, R. D.; Bernhardsson, A.; Berning, A.; Celani, P.; Cooper, D. L.; Deegan, M. J. O.; Dobbyn, A. J.; Eckert, F.; Hampel, C.; Hetzer, G.; Korona, T.; Lindh, R.; Lloyd, A W.; McNicholas, S. J.; Manby, F. R.; Meyer, W.; Mura, M. E.; Nicklass, A.; Palmieri, P.; Pitzer, R.; Rauhut, G.; Schütz, M.; Stoll, H.; Stone, A. J.; Tarroni, R.; Thorsteinsson, T. 1998.

(75) Varandas, A. J. C. Chem. Phys. Lett. 1992, 194, 333-340.

(76) Varandas, A. J. C.; Biczysko, M.; Poveda, L. A. Manuscript to be submitted for publication.

(77) Langhoff, S. R.; Davidson, E. R. Int. J. Quantum Chem. 1974, 8, $61-72$.

(78) Biczysko, M.; Poveda, L. A.; Varandas, A. J. C. Chem. Phys. Lett. 2006, 424, 46-53.

(79) Biehl, H.; Stuhl, F. J. Chem. Phys. 1994, 100, 141.

(80) Martin, J. M. L.; Taylor, P. R. Mol. Phys. 1999, 96, 681

(81) Walch, S.; Partridge, H. Chem. Phys. Lett. 1995, 233, 331-334.

(82) Ho, T.-S.; Rabitz, H.; Aoiz, J. F.; Banares, L.; Vazquez, S. A.; Harding, L. B. J. Chem. Phys. 2003, 109, 3063.

(83) Pascual, R.; Schatz, G. C.; Lendvay, G.; Troya, D. J. Phys. Chem. A 2002, 106, 4125 .

(84) Adam, L.; Hack, W.; Zhu, H.; Qu, Z.-W.; Schinke, R. J. Chem. Phys. 2005, 122, 114301

(85) Chu, T.-S.; Han, K.-L.; Varandas, A. J. C. J. Phys. Chem. A 2006 $110,1666-1671$

(86) Varandas, A. J. C.; Chu, T.-S.; Han, K.-L.; Caridade, P. J. S. B. Chem. Phys. Lett. 2006, 421, 415-420.

(87) Caridade, P. J. S. B.; Rodrigues, S. P. J.; Sousa, F.; Varandas, A.

J. C. J. Phys. Chem. A 2005, 109, 2356-2363.

(88) Holloway, S.; Halstead, D.; Hodgson, A. J. Electron. Spectrosc. Relat. Phenom. 1987, 45, 207.

(89) Haase, G.; Asscher, M.; Kosloff, R. J. Chem. Phys. 1989, 90, 3346. (90) Billing, G. D.; Guldberg, A.; Henriksen, N. E.; Hansen, F. Y. Chem. Phys. 1990, 147, 1

(91) Hansen, F. Y.; Henriksen, N. E.; Billing, G. D. Surf. Sci. 1995 324,55 .

(92) Romm, L.; Katz, G.; Kosloff, R.; Asscher, M. J. Phys. Chem. B 1997, 101, 2213.

(93) Romm, L.; Citri, O.; Kosloff, R.; Asscher, M. J. Chem. Phys. 2000, 112,8821 .

(94) van Harrevelt, R.; Honkala, K.; Nørskov, J. K.; Manthe, U. J. Chem. Phys. 2005, 122, 234702.

(95) Yamamoto, T. J. Chem. Phys. 1960, 33, 281.

(96) Miller, W. H. J. Chem. Phys. 1974, 61, 1823.
(97) Miller, W. H.; Schwartz, S. D.; Tromp, J. W. J. Chem. Phys. 1983 , 79, 4889 .

(98) Manthe, U. J. Theor. Comput. Chem. 2002, 1, 153.

(99) Meyer, H.-D.; Manthe, U.; Cederbaum, L. S. Chem. Phys. Lett. 1990, 165, 73.

(100) Manthe, U.; Meyer, H.-D.; Cederbaum, L. S. J. Chem. Phys. 1992 97, 3199 .

(101) Beck, M. H.; Jäckle, A.; Worth, G. A.; Meyer, H.-D. Phys. Rep. 2000, 324, 1 .

(102) van Harrevelt, R.; Honkala, K.; Nørskov, J. K.; Manthe, U. J. Chem. Phys. 2006, 124, 026102 .

(103) Honkala, K.; Hellman, A.; Remediakis, I. N.; Logadottir, A.; Carlsson, A.; Dahl, S.; Christensen, C. H.; Nørskov, J. K. Science 2005, 307, 555-558.

(104) Perdew, J. P.; Chevary, J. A.; Vosko, S. H.; Jackson, K. A.; Pederson, M. R.; Singh, D. J.; Fiolhais, C. Phys. Rev. B 1992, 46, 66716687.

(105) Hammer, B.; Hansen, L. B.; Nørskov, J. K. Phys. Rev. B 1999, $59,7413-7421$

(106) Neugebauer J.; Scheffler, M. Phys. Rev. B 1992, 46, 1606716080

(107) Velde G. T.; Baerends, E. J. Chem. Phys. 1993, 177, 399-406.

(108) Busnengo, H. F.; Salin, A.; Dong, W. J. Chem. Phys. 2000, 112, $7641-7651$.

(109) Olsen, R. A.; Busnengo, H. F.; Salin, A.; Somers, M. F.; Kroes, G. J.; Baerends, E. J. J. Chem. Phys. 2002, 116, 3841-3855.

(110) Gross, A.; Wilke, S.; Scheffler, M. Phys. Rev. Lett. 1995, 75 , $2718-2721$

(111) Kroes, G. J.; Baerends, E. J.; Mowrey, R. C. Phys. Rev. Lett. 1997, 78, 3583-3586.

(112) Pijper, E.; Kroes, G. J.; Olsen, R. A.; Baerends, E. J. J. Chem Phys. 2002, 117, 5885-5898.

(113) Busnengo, H. F.; Pijper, E.; Somers, M. F.; Kroes, G. J.; Salin A.; Olsen, R. A.; Lemoine, D.; Dong, W. Chem. Phys. Lett. 2002, 356, $515-522$.

(114) Bligaard, T.; Honkala, K.; Logadottir, A.; Nørskov, J. K.; Dahl, S.; Jacobsen, C. J. H. J. Phys. Chem. B 2003, 107, 9325-9331.

(115) Luppi, M.; Olsen, R. A.; Baerends, E. J. Phys. Chem. Chem. Phys. 2006, 6, 688-696.

(116) Hammer, B.; Hansen, L.; Nørskov, J. K. Phys. Rev. B 1999, 59 , 7413. Bahn S. R.; Jacobsen, K. W. Comput. Sci. Eng. 2002, 4 (3), 56. The DACAPO code can be downloaded at http://www.fysik.dtu.dk/campos.

(117) Di Csare, M. A.; Busnengo, H. F.; Dong, W.; Salin, A. J. Chem Phys. 2003, 118, 11226.

(118) Riviere, P.; Busnengo, H. P.; Martin, F. J. Chem. Phys. 2004 121,751 .

(119) Vincent, J. K.; Olsen, R. A.; Kroes, G. J.; Luppi, M.; Baerends, E. J. J. Chem. Phys. 2005, 122, 044701

(120) Kosloff, R. J. Phys. Chem. 1988, 92, 2087-2100.

(121) Corey, G. C.; Lemoine, D. J. Chem. Phys. 1992, 97, 4115.

(122) Feit, M. D.; Fleck, J. A.; Steiger, A. J. Comput. Phys. 1982, 47, 412.

(123) Balint-Kurti, G. G.; Dixon, R. N.; Marston, C. C. J. Chem. Soc. Faraday Trans. 1990, 86, 1741.

(124) Vincent, J. K.; Olsen, R. A.; Kroes, G. J.; Baerends, E. J. Surf. Sci. 2004, 573, 433-445.

(125) Luntz, A. C.; Brown, J. K.; Williams; M. D. J. Chem. Phys. 1990, 93,5240 .

(126) Dai, J.; Light, J. C. J. Chem. Phys. 1997, 107, 1676-1679.

(127) Hammer B.; Nørskov, J. K. Nature 1995, 376, 238.

(128) Olsen, R. A.; Kroes, G. J.; Baerends, E. J. J. Chem. Phys. 1999, 111,11155

(129) Perdew, J. P.; Chevary, J. A.; Vosko, S. H.; Jackson, K. A. Pederson, M. R.; Singh, D. J.; C. Fiolhais, C. Phys. Rev. B 1992, 46, 66716687.

(130) Nieto, P.; Pijper, E.; Barredo, D.; Laurent, G.; Olsen, R. A.; Baerends, E. J.; Kroes, G. J.; Farías, D. Science 2006, 312, 86-89. 611.

(131) Zhang, C.; Liu Z.-P.; Hu, P. J. Chem. Phys. 2001, 115, 609-

(132) Skodje, R. T.; Truhlar D. G.; Garrett, B. C. J. Phys. Chem. 1981 $85,3019-3023$

(133) Clary, D. C. Science 1998, 279, 1879-1882

(134) Tautermann, C. S.; Clary, D. C. J. Chem. Phys. 2005, 122, 134702.

(135) Tautermann, C. S.; Clary, D. C. Phys. Chem. Chem. Phys. 2006, $8,1437-1444$.

(136) Stechel, E. B.; Walker, R. B.; Light, J. C. J. Chem. Phys 1978, $69,3518-3531$

(137) Van Hardeveld, R.; Van Montfoort, A. Surf. Sci. 1966, 4, 396

(138) Jacobsen, C. J. H.; Dahl, S.; Hansen, P. L.; Törnqvist, E.; Jensen, L.; Topsøe, H.; Prip, D. V.; Møenshaug, P. B.; Chorkendorff, I. J. Mol. Catal. A 2000, 163, 19. 
(139) Hellman, A.; Honkala, K.; Remediakis, I. N.; Logadottir, A.; Carlsson, A.; Dahl, S.; Christensen, C. H.; Nørskov, J. K. Surf. Sci., in press.

(140) Landau, D. P.; Binder, K. A guide to monte carlo simulations in statistical physics; Cambridge University Press: Cambridge, U.K., 2000.

(141) Christensen, C. H.; Sørensen, R. Z.; Johannessen, T.; Quaade, U. J.; Honkala, K.; Elmøe, T. D., Køhler; R., Nørskov, J. K. J. Mater Chem. 2005, 15, 4106.

(142) Hinnemann, B.; Nørskov, J. K. Top. Catal. 2006, 37, 55-70.
(143) Nørskov, J. K.; Rossmeisl. J.; Logadottir, A.; Lindqvist, L.; Kitchin, J. R.; Bligaard, T.; Jonsson, H. J. Phys. Chem. B 2004, 108, 17886.

(144) Nørskov, J. K.; Bligaard, T.; Logadottir, A.; Kitchin, J. R.; Chen, J. G.; Pandelov, S.; Stimming, U. J. Electrochem. Soc. 2005, 152, J23.

(145) Skulason, E.; Bligaard, T.; Rossmeisl, J.; Logadottir, A.; Nørskov, J. K.; Jonsson, H. Manuscript to be submitted for publication. 